\title{
How to Use SNP_TATA_Comparator to Find a Significant Change in Gene Expression Caused by the Regulatory SNP of This Gene's Promoter via a Change in Affinity of the TATA-Binding Protein for This Promoter
}

\author{
Mikhail Ponomarenko, ${ }^{1,2}$ Dmitry Rasskazov, ${ }^{1}$ Olga Arkova, ${ }^{1}$ Petr Ponomarenko, ${ }^{3}$ \\ Valentin Suslov, ${ }^{1}$ Ludmila Savinkova, ${ }^{1}$ and Nikolay Kolchanov ${ }^{1,2}$ \\ ${ }^{1}$ Institute of Cytology and Genetics, Siberian Branch of Russian Academy of Sciences, Novosibirsk 630090, Russia \\ ${ }^{2}$ Department of Natural Sciences, Novosibirsk State University, Novosibirsk 630090, Russia \\ ${ }^{3}$ Children's Hospital Los Angeles, University of Southern California, Los Angeles, CA 90027, USA
}

Correspondence should be addressed to Mikhail Ponomarenko; pon@bionet.nsc.ru

Received 3 July 2015; Accepted 24 August 2015

Academic Editor: Jorge H. Leitão

Copyright (C) 2015 Mikhail Ponomarenko et al. This is an open access article distributed under the Creative Commons Attribution License, which permits unrestricted use, distribution, and reproduction in any medium, provided the original work is properly cited.

\begin{abstract}
The use of biomedical SNP markers of diseases can improve effectiveness of treatment. Genotyping of patients with subsequent searching for SNPs more frequent than in norm is the only commonly accepted method for identification of SNP markers within the framework of translational research. The bioinformatics applications aimed at millions of unannotated SNPs of the "1000 Genomes" can make this search for SNP markers more focused and less expensive. We used our Web service involving Fisher's $Z$-score for candidate SNP markers to find a significant change in a gene's expression. Here we analyzed the change caused by SNPs in the gene's promoter via a change in affinity of the TATA-binding protein for this promoter. We provide examples and discuss how to use this bioinformatics application in the course of practical analysis of unannotated SNPs from the "1000 Genomes" project. Using known biomedical SNP markers, we identified 17 novel candidate SNP markers nearby: rs549858786 (rheumatoid arthritis); rs72661131 (cardiovascular events in rheumatoid arthritis); rs562962093 (stroke); rs563558831 (cyclophosphamide bioactivation); rs55878706 (malaria resistance, leukopenia), rs572527200 (asthma, systemic sclerosis, and psoriasis), rs371045754 (hemophilia B), rs587745372 (cardiovascular events); rs372329931, rs200209906, rs367732974, and rs549591993 (all four: cancer); rs17231520 and rs569033466 (both: atherosclerosis); rs63750953, rs281864525, and rs34166473 (all three: malaria resistance, thalassemia).
\end{abstract}

\section{Introduction}

Biomedical SNP (single nucleotide polymorphism) markers are significantly frequent differences of personal genomes of patients from the reference human genome, hg19. The discovery of SNP markers of hypersensitivity to the HIV-1 reverse transcriptase inhibitor Ziagen in the $H L A-B$ gene of the human major histocompatibility complex [1] prevented deaths of thousands of patients. That is the reason why a search for candidate SNP markers of diseases now represents the bulk of bioinformatics studies aimed at the development of so-called postgenomic predictive preventive personalized medicine, PPPM [2].
In the 20th century, discovery of SNPs and of the resulting associations with diseases was casual, whereas the postgenomic search for SNPs is systematic and large-scale: it includes the largest worldwide project " 1000 Genomes" [3]. Researchers maintaining the dbSNP database [4] accumulate and annotate proven SNPs and continuously refine the human reference genome (ho19), namely, the ancestral variants for all SNPs within the Ensembl [5] and GENCODE v. 19 [6] databases available from the public UCSC Genome Browser [7]. The biomedical databases GWAS (genome-wide association study) [8], OMIM [9], ClinVar [10], and HapMap [11] supplement these SNPs by documenting associations with diseases, with one another, and with the pathogenic 
haplotypes (e.g., [12]). Furthermore, researchers project these SNPs onto the whole-genome maps of genes, protein-binding sites on DNA predicted in silico and/or detected in vivo using chromatin immunoprecipitation (ChIP), interchromosomal contacts, and nucleosome packaging as well as transcriptomes in health [13] and disease in different tissues [14] and after treatment [15]. Accordingly, the available Web services (e.g., [16-27]) facilitate the bioinformatics search for relevantto-medicine candidate SNP markers in terms of ranking of unannotated SNPs by their similarity to known biomedical SNP markers, according to projections of these SNPs onto the whole-genome maps. The Central Limit Theorem means [28] that the accuracy of such a search should increase asymptotically with an increase in accuracy, volume, representativeness, completeness, the number, and diversity of the whole-genome maps as well as due to refinement of empirical analyses of similarity between projections of SNPs onto genomic maps [16]. This way, the best research progress has been achieved for many thousands of SNPs within proteincoding regions of genes [9] due to the invariant types of disruption in both structure and function of the affected proteins regardless of the cellular conditions [29]. At the same time, the worst research progress has been made for a few hundred of so-called regulatory SNPs $[4,9,23,24]$ because their manifestations are dependent on cellular conditions [30].

For the present study, it was helpful that an intermediate position between these extremes belongs to SNPs in the DNA sites binding to the TATA-binding protein (TBP); these SNPs constitute $\sim 10 \%$ of all the known regulatory SNP markers relevant to medicine, whereas TBP is only one of 2600 known DNA-binding proteins in humans [31]. The above-mentioned special place of such SNPs can be mostly explained by the necessity of a TBP-binding site within the $[-70 ;-20]$ region of the promoter for any mRNA [32] because RNA polymerase II binds to the anchoring complex TBP-promoter, and this event triggers assembly of the transcription preinitiation complex for this mRNA [33]. These results were obtained in studies on unviability of TBP-null animals [34] or animals harboring a knockdown [35] of the TBP gene. Besides, ChIP data confirmed that the TATA-like motifs are the TBPbinding sites in gene promoters in yeast [36] and in mice [37], as did the results of in silico analysis and their selective verification by means of in vivo bioluminescence among human genes [38]. Finally, SNPs in the TBP-binding sites invariantly cause gene overexpression in relation to SNPcaused enhancement of the TBP/promoter affinity as well as the deficient expression of genes as a result of an SNP-caused reduction in this affinity regardless of any cellular conditions; these phenomena have been repeatedly demonstrated in independent experiments [39-41]. This stability of the SNPcaused alterations in the $\mathrm{TBP} /$ promoter-affinity resembles the invariant relation of SNPs in protein-coding gene regions with protein structure/function, rather than such relations involving regulatory SNPs, whose effects strongly depend on the tissue, cell type, and so forth.

In our previous studies, we measured in vitro affinity values of TBP for the representative sets of aptamers of synthetic single-stranded DNA (ssDNA) [42] and doublestranded DNA (dsDNA) [43] including natural TBP-binding sites of human gene promoters [44] that are stored in our database ACTIVITY [45]. Next, we derived formulas for in silico prognosis of the TBP-ssDNA [46], TBP-dsDNA [43], and TBP-promoter [47] affinity using the widely accepted Bucher's criterion [48] for the canonical TBP-binding sites, the so-called TATA box (synonyms: Goldberg-Hogness box and Hogness box [32]), in the three-step mechanism of the TBP binding to a promoter [47]. This mechanism was observed independently in vitro a year later [49]. Then we confirmed predictions of this three-step empirical predictive bioinformatics model [47] at equilibrium [50], without equilibrium [51], and in real time [52, 53] in vitro. Additionally, we compiled a set of SNPs in the TBP-binding sites associated with human diseases [54], including the AIDS pandemic [55], and with commercially important traits of plants and animals [56]. Then, we confirmed the three-step predictions by means of these SNPs [57] and by means of transcriptomes of the human brain [58], the auxin response in plants [59, 60], and the data from 68 independent experiments (for review, see [61]). To finalize this comprehensive verification of the threestep model of TBP binding to a promoter $[47,49]$, we created a freely available Web service [62] for users who wish to apply this bioinformatics application to data on the TBP/promotercomplexes in humans: http://beehive.bionet.nsc.ru/cgi-bin/ mgs/tatascan/start.pl.

In this work, we updated our review of SNPs (in the TBPbinding sites) associated with human diseases [54] using the standard keyword search, using existing data from the literature [63], in NCBI databases [4] and provide examples on how to use our Web service [62] to find a significant change in a gene's expression when this change is caused by the regulatory SNP in this gene's promoter via a change in the TBP affinity for the promoter. Using a representative set of socalled control data on the total number of 62 SNPs, we show the output of our bioinformatics applications. Using this approach, for the known SNP markers relevant to medicine, we present 17 novel candidate SNP markers that are located nearby, namely, rs549858786 of the IL1B gene (associated with rheumatoid arthritis), rs63750953 and rs281864525 (both: $H B B$; malaria resistance and $\beta$-thalassemia), rs34166473 (HBD; malaria resistance and $\delta$-thalassemia), rs563558831 (CYP2B6; better bioactivation of cyclophosphamide), rs372329931 (ADH7; esophageal cancer), rs562962093 (MBL2; stroke, preeclampsia, and variable immunodeficiency), rs72661131 (MBL2; cardiovascular events in rheumatoid arthritis), rs17231520 and rs569033466 (both: CETP; atherosclerosis), rs55878706 (DARC; low whiteblood-cell count and resistance to malaria), rs367732974 and rs549591993 (both: F7; progression of colorectal cancer from a primary tumor to metastasis), rs572527200 (MMP12; low risks of asthma, systemic sclerosis, and psoriasis), rs371045754 (F9; Leiden hemophilia B), rs200209906 (GSTM3; brain, lung, and testicular cancers), and rs587745372 (GJA5, arrhythmia and cardiovascular events). This is the principal result of this work.

\section{Methods}

2.1. Web-Service SNP_TATA_Comparator. Web service SNP TATA_Comparator http://beehive.bionet.nsc.ru/cgi-bin/mgs/ tatascan/start.pl [62] is a bioinformatics application installed 


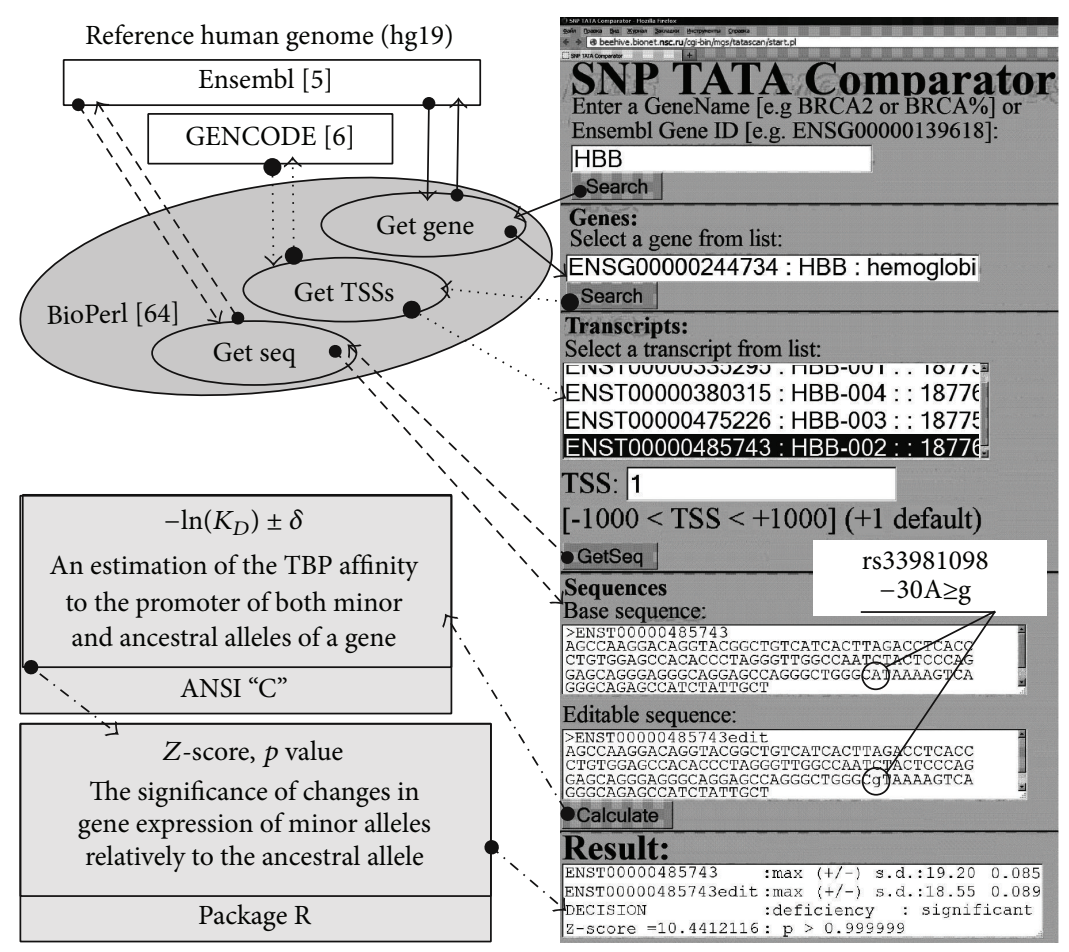

(a)

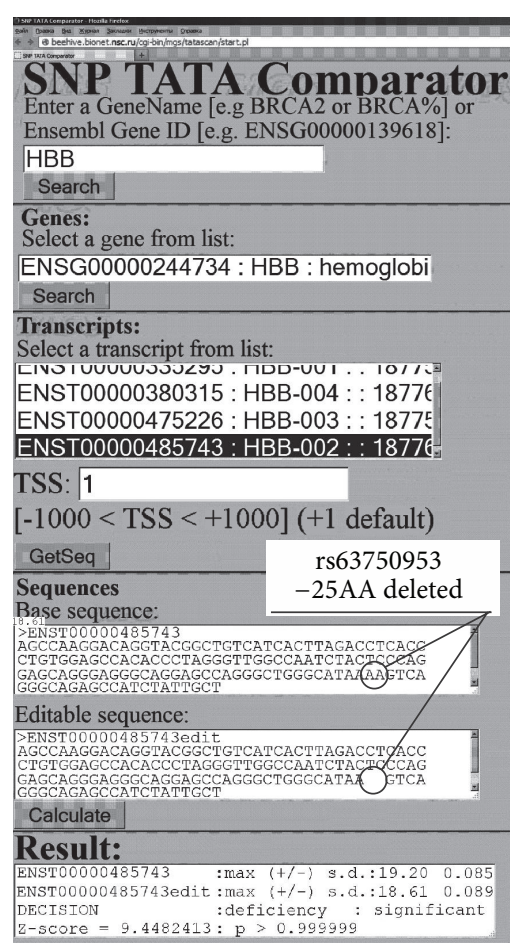

(b)

FIgURE 1: How to use the Web service SNP_TATA_Comparator [62] to find a significant change in gene expression caused by SNPs of this gene's promoter via a change in affinity of the TATA-binding protein (TBP) for this promoter in the cases of (a) a known biomedical SNP marker and (b) a nearby candidate SNP marker. Solid, dotted, and dashed arrows are the gene, transcript, and sequence lists, respectively, from Ensembl [5] and GENCODE [6] databases of the reference human genome, hg19. Dash-and-dot arrows are an estimate of the statistical significance ( $Z$-score, $p$ value) of deviation of the gene expression in patients carrying minor alleles, relative to the ancestral allele, (1)-(4) and Algorithm 1.

on the hybrid cluster supercomputer HKC-30T (Hewlett Packard, Palo Alto, CA, US) based on the Intel Xeon 5450 platform of 85-Tflop performance under OS Red Hat Enterprise Linux 5.4 that is supported by the Siberian Supercomputer Center (Novosibirsk, Russia).

One can see screenshots of the user interface of this software in Figure 1 and all the data flowcharts (arrows) between them and two databases Ensembl [5] and GENCODE v. 19 [6] of the human reference genome, hg19, in Figure 1(a). Using the standard method, we encoded this interface in the dynamic programming language JavaScript and created these flowcharts by means of the BioPerl toolkit [64]. Using the online mode of these modules, a user can prepare input data for the executable applet encoded primarily in the programming language $C$ of the ANSI standard and, then, run this applet (the "Calculate" button). These input data consist of two variants-ancestral (the "Base sequence" window) and minor (the "Editable sequence" window) — of the 90 bp DNA sequence $\left\{s_{-90} \cdots s_{i} \cdots s_{-1}\right\}$ in the proximal core-promoter region immediately upstream of the transcription start site (TSS, $s_{0}$ ) of interest within the human reference genome, hg19 (where $s_{i} \in\{a, c, g, t\}$ ). One can find our description of the bioinformatics model of this executable applet within the next Section 2.2.
One more example of the output data from the abovementioned executable applet is shown within the two top lines of the "Result" window in Figure 1(b). These data include the maximum value, $-\ln \left(K_{D}\right) \pm \delta$, among all the possible estimates of the TBP binding affinity for the $26 \mathrm{bp}$ DNA fragment, $\left\{s_{i-13} \cdots s_{i} \cdots s_{i+12}\right\}$ at the $i$ th position ranging from -70 to -20 for both DNA chains $[32,59]$. Here, $K_{D}$ is the equilibrium dissociation constant (expressed in the units of mol per liter; M) of the TBP binding to the ancestral or minor allele of the promoter under study. These quantitative estimates of the SNP-caused change in the TBP-promoter affinity are the input data for another executable applet coded primarily by means of the standard statistical package in the $\mathrm{R}$ software. We provided examples of its output data within the bottom line of the "Result" window in Figure 1. These are Fisher's $Z$-score value along with its probability rate, $p$ (where $\alpha=1-p$, statistical significance). Within the "Decision" line, one can see the prediction made by our Web service, namely, (i) "excess" for overexpression of the gene after the SNP-caused significant increase in the TBP binding affinity for the minor allele of the gene promoter or (ii) "deficiency" for lowered expression of this gene in the opposite case. This prediction is the main result of the proposed Web service [62]. 
IF $\left\{-\ln \left(K_{D ; \text { MINOR }}\right)\right.$ is statistically significantly greater than $\left.-\ln \left(K_{D ; \text { ANCESTRAL }}\right)\right\}$,

THEN \{DECISION is "there is an excess of the minor allele of a given gene versus the ancestral allele"\}; ELSE [IF $\left\{-\ln \left(K_{D ; M I N O R}\right)\right.$ is statistically significantly less than $\left.-\ln \left(K_{D ; A N C E S T R A L}\right)\right\}$,

THEN \{DECISION is "there is a deficiency of the minor allele of this gene versus the ancestral allele" $\}$ ];

OTHERWISE \{DECISION is "alteration of the expression of this gene is insignificant"\}.

Algorithm 1

2.2. The Bioinformatics Model. The bioinformatics model that we use here is the three-step approximation of the TBP binding to the $[-70 ;-20]$ region of the core-promoters of eukaryotic genes; this approximation was first suggested by us [47] on the basis of our original experimental data [4244] and, then, this three-step approximation was discovered independently [49] a year later. Within the framework of this model, (i) TBP binds nonspecifically to DNA and slides along this molecule $\leftrightarrow$ (ii) the sliding of TBP stops at a proper TBPbinding site $\leftrightarrow$ the DNA helix bends from the $19^{\circ}$ angle to the $90^{\circ}$ angle [65] and stabilizes the local TBP-promoter complex. This interaction (binding affinity) can be estimated using the following empirical equation:

$$
\begin{aligned}
- & \ln \left(K_{D}\right) \\
= & 10.9 \\
& -0.2\left\{\ln \left(K_{\mathrm{SLIDE}}\right)+\ln \left(K_{\mathrm{STOP}}\right)+\ln \left(K_{\mathrm{BEND}}\right)\right\},
\end{aligned}
$$

where 10.9 (ln units) is nonspecific TBP-DNA affinity $10^{-5} \mathrm{M}$ [66], 0.2 is the stoichiometric coefficient [47], and $K_{\text {STOP }}$ is the maximal score value of Bucher's position-weight matrix, which is the commonly accepted criterion of the TATA box: the canonical form of the TBP-binding site [48].

In (1), $K_{\text {SLIDE }}$ is our empirical estimate of the equilibrium constant of the TBP sliding along DNA that was determined experimentally [67]; namely,

$$
\begin{array}{r}
-\ln \left(K_{\mathrm{SLIDE}}\right)=\mathrm{MEAN}_{15 \mathrm{bp}}\left\{0.8[\mathrm{TA}]_{3^{\prime} \mathrm{HALF}}\right. \\
\left.-3.4 \text { MinorGrooveWidth }{ }_{\text {CENTER }}-35.1\right\}
\end{array}
$$

where $[\mathrm{TA}]_{3^{\prime} \mathrm{HALF}}$ is the total number of instances of dinucleotide TA within the $3^{\prime}$-half of the DNA sequence treated; MinorGrooveWidth REGION is the mean width of the minor groove of the B-form of the DNA helix [68]; 0.8, -3.4, and -35.1 are linear regression coefficients determined by means of our experimental data [43] stored in our database ACTIVITY [45]; MEAN $_{15 \text { bp }}$ is the mean arithmetic value for all possible positions and orientations of the TBP-binding site (15 bp long) that was determined empirically [67].

In (1), $K_{\mathrm{BEND}}$ is our empirical estimate of the equilibrium constant at the DNA helix bending step on the basis of the macromolecular dynamics computations [65] describing how TBP can bind to DNA; namely,

$$
\begin{aligned}
& -\ln \left(K_{\text {BEND }}\right)=\text { MEAN }_{\text {TATA-box }}\left\{0.9[\mathrm{WR}]_{\text {FLANK }}\right. \\
& \left.+2.5[\mathrm{TV}]_{\text {CENTER }}+14.4\right\}
\end{aligned}
$$

where $\mathrm{WR}=\{\mathrm{TA}, \mathrm{AA}, \mathrm{TG}, \mathrm{AG}\}$ and $\mathrm{TV}=\{\mathrm{TA}, \mathrm{TC}, \mathrm{TG}\}$ [46] (the IUPAC-IUB nomenclature [69]); 0.9, 2.5, and 14.4 are linear regression coefficients calculated from our experimental data [42] stored in our database ACTIVITY [45]; MEAN $\mathrm{NATA-box}_{\text {is }}$ is mean arithmetic value for both DNA strands of the TBP-binding site at the position of the maximal score value of Bucher's position-weight matrix [48].

Additionally, the standard deviation of the $-\ln \left[K_{D}\right]$ estimates (see (1)) - for all the 78 possible mononucleotide substitutions, $s_{i+j} \rightarrow \xi$, at each $j$ th position $(-13 \leq j \leq 12$; $3 \times 26$ ) within the $26 \mathrm{bp}$ DNA window centered by $i$ th position of the promoter DNA analyzed-was heuristically estimated as

$$
\delta=\left[\frac{\left(\Sigma_{1 \leq i \leq 26} \Sigma_{\xi \in\{a, c, g, t\}}\left[\ln \left(K_{D}\left(\left\{s_{i-13} \cdots s_{i+j-1} \xi s_{i+j+1} \cdots s_{i+12}\right\}\right) / K_{D}\left(\left\{s_{i-13} \cdots s_{i+j-1} s_{i+j} s_{i+j+1} \cdots s_{i+12}\right\}\right)\right)^{2}\right]\right)}{78}\right]^{1 / 2}
$$

This equation (4) estimates the resistance against the majority of SNPs in the case of the biologically essential complex of TBP binding to the TBP-binding site of the promoters [55].

Finally, the results of (1)-(4) on the promoter DNA sequences of two minor and ancestral alleles of a given gene are compared with one another in terms of Fisher's $Z$-score and its probability rate, that is, the $p$ value (where $\alpha=1-p$ is the statistical significance level). On this basis, a decision is made.
For each SNP processed, the decision (Algorithm 1) is the main result of the bioinformatics model used.

2.3. How to Use SNP_TATA_Comparator. Practical use of our Web service [62] is illustrated in Figure 1 and documented in Tables 1-3. In this work, we analyzed in silico 31 human genes containing 40 known biomedical SNP markers in their core-promoter from our review [54], which was updated in the present work. Using the UCSC Genome Browser [7], we found 163 additional unannotated SNPs nearby that were 


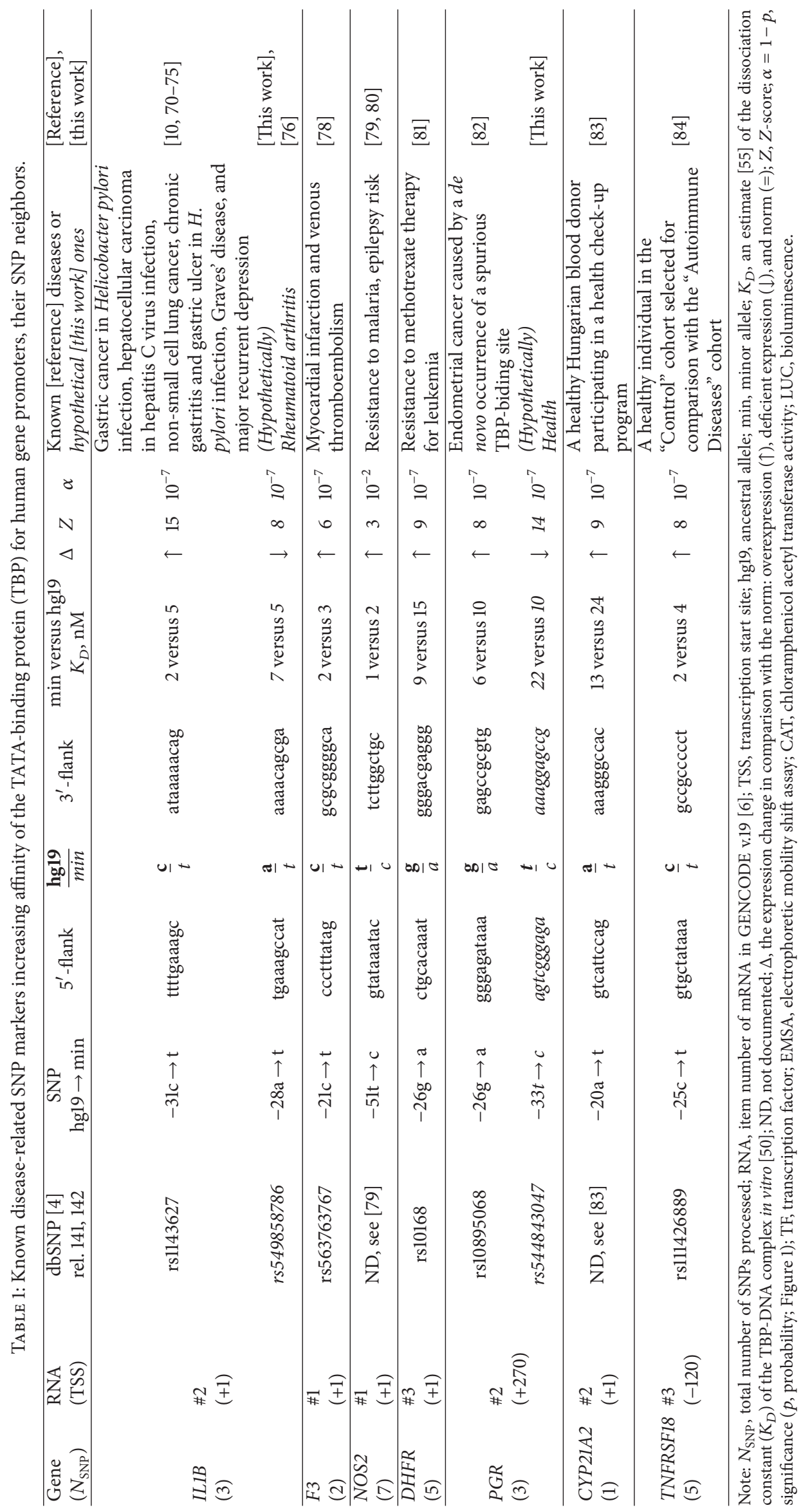




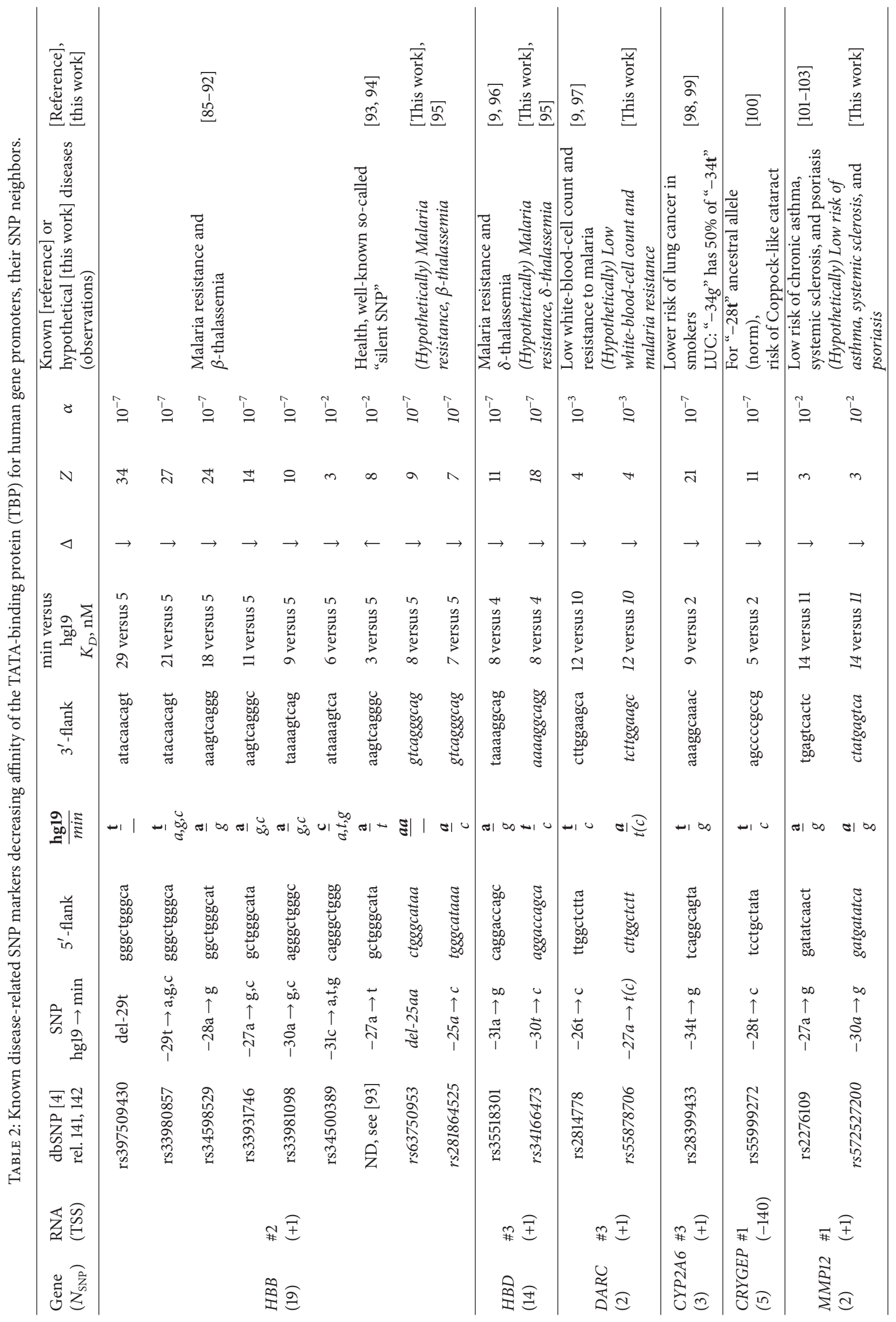




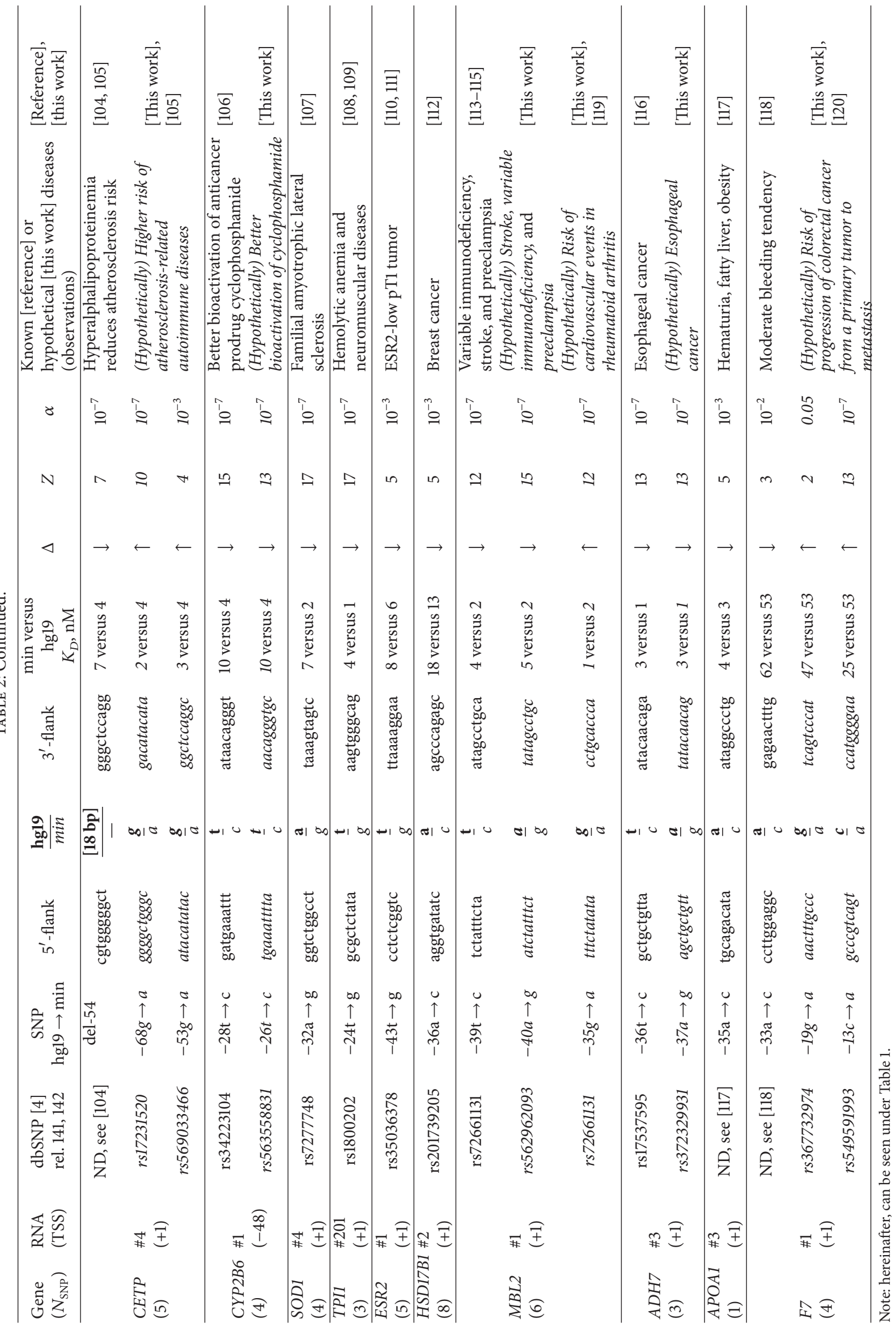




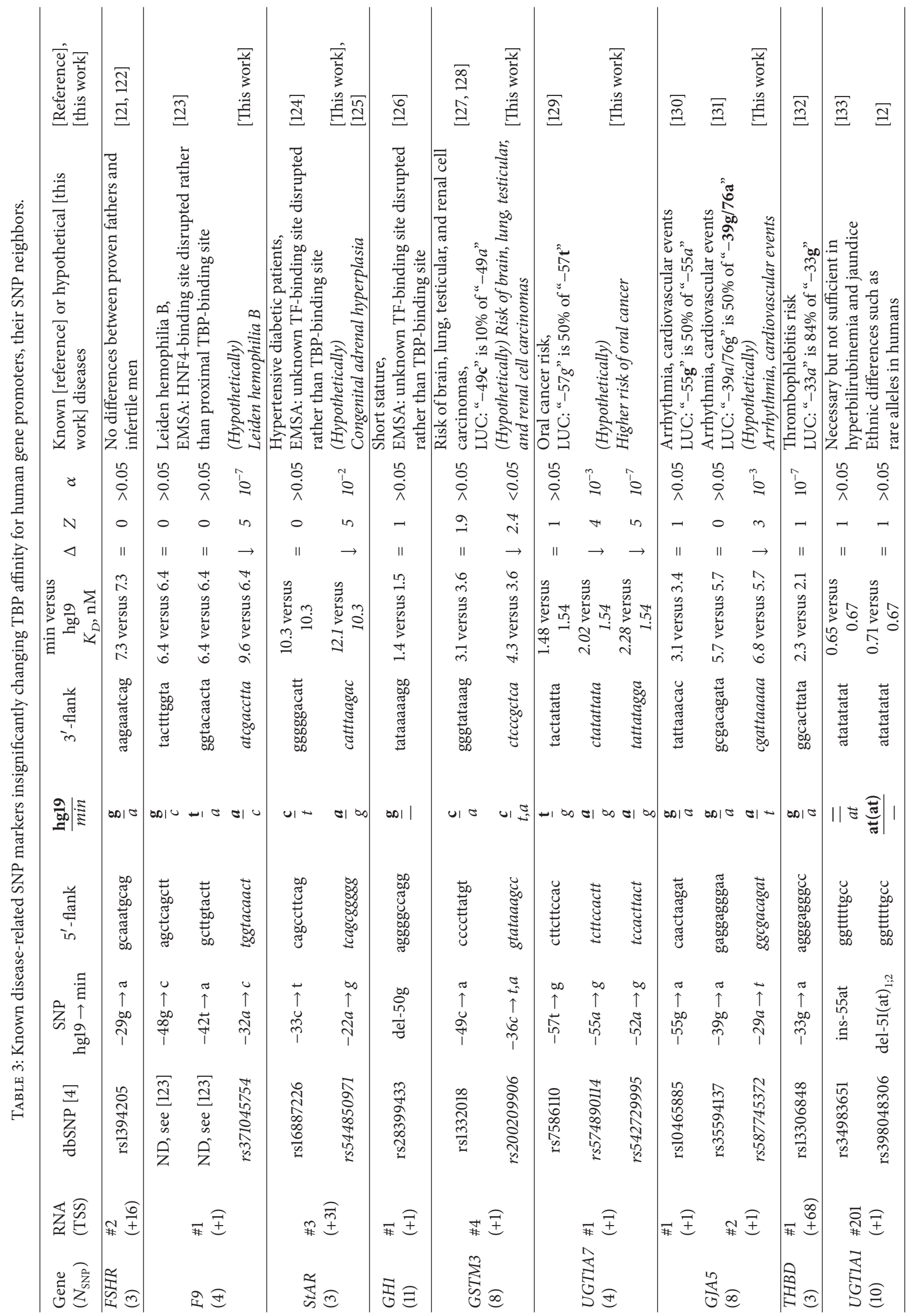


detected in the "1000 Genomes" project [3]. Thus, the total number of the DNA sequences processed was 203.

We used the ancestral variants of these SNPs from Ensembl [5] using the GENCODE v. 19 [6]; we also constructed their minor alleles by hand in "online real-time" mode according to the dbSNP entries [4] and/or literature sources in the case of the SNPs undocumented in this database as shown in Figure 1 and in Tables 1-3. We analyzed each of the 203 SNPs independently from one another. As a result, for most of the unannotated SNPs analyzed, we found insignificant changes in TBP affinity for human promoters: 142 of 163 or $90 \%$ of SNPs (data not shown).

Finally, the remaining 17 of the 163 unannotated SNPs (10\%) appeared to be new candidate biomedical SNP markers near the existing markers. We italicized and labeled them with the marks "hypothetical" and "this work" in Tables 13. We found associations of both known and possible nearby SNP markers with the same human diseases in the case of their codirectional effects on gene expression; otherwise, we did an additional keyword search $[54,63]$ in NCBI databases [4] and recorded the results below the above-mentioned marks "hypothetical" and "this work." These 17 new candidate biomedical SNP markers are the main result of the present study on how to use the proposed Web service [62] in practice.

\section{Results}

3.1. The Results on Seven Known Biomedical SNP Markers That Increase TBP Affinity for Human Gene Promoters. The results on seven known biomedical SNP markers that increase TBP affinity for human gene promoters are presented in Table 1. The most widely studied among them is rs1143627, a substitution of minor $\mathrm{T}$ for ancestral $\mathrm{C}$ at position -31 (hereafter denoted as $-31 \mathrm{C} \rightarrow \mathrm{T}$ ) in the core-promoter for transcript number 2 of the human $I L 1 B$ gene (interleukin $1 \beta$ ). Let us analyze it in detail so that we can later briefly describe the rest of our SNPs on the basis of this example.

As one can see in Table 1, this SNP transforms a noncanonical TBP-binding site to the canonical TATA-box, namely, gaaagC ${ }_{-31}$ ATAAAAcag $\rightarrow$ gaaagT ${ }_{-31}$ ATAAAAcag. Obviously, the minor allele $-31 \mathrm{~T}$ can significantly increase TBP affinity for the $I L 1 B$ promoter relative to the ancestral one, -31C. According to (1)-(4) and Algorithm 1, their estimate $K_{D}=2 \mathrm{nM}$ (Table 1 ), in the case of $-31 \mathrm{~T}$, is significantly greater $\left(Z\right.$-score $\left.=14.56, \alpha<10^{-6}\right)$ than $K_{D}=5 \mathrm{nM}$ in case of $-31 \mathrm{C}$. According to three independent empirical studies [39-41], this significant increase in TBP affinity for the minor variant of the $I L 1 B$ promoter corresponds to overexpression of this gene (designated as $\uparrow$ in Tables 1-3). This prediction is consistent with clinical findings: overexpression of interleukin $1 \beta$ in gastric cancer with Helicobacter pylori infection $[10,70]$, in hepatocellular carcinoma with infection by hepatitis $\mathrm{C}$ virus [71], in non-small cell lung cancer in smokers and during alcohol dependence [72], as well as in nonneoplastic chronic gastritis and gastric ulcer [73], in intractable Graves' autoimmune disease [74], and even in a neurodegenerative disorder during major recurrent depression [75]. Thus, the prediction by the Web service [62] (see (1)-(4) and Algorithm 1) is consistent with a number of independent clinical studies [70-75].

Using the UCSC Genome Browser [7], we found the unannotated SNP rs549858786 $(-28 \mathrm{~A} \rightarrow \mathrm{T})$ positioned $4 \mathrm{bp}$ downstream of the above-mentioned known SNP marker rs1143627 $(-31 \mathrm{C} \rightarrow \mathrm{T})$. As one can see in Figure 1(b), our Web service [63] predicts (see (1)-(4) and Algorithm 1) the affinity of TBP for the minor allele $-28 \mathrm{~T}$ of the promoter analyzed: $7 \mathrm{nM}$ (Table 1); this result is significantly less than the norm: $5 \mathrm{nM}\left(Z\right.$-score $\left.=7.63, \alpha<10^{-6}\right)$. According to some studies [39-41], this significant decrease in TBP affinity for the $I L 1 B$ promoter corresponds to an interleukin $1 \beta$ deficiency in patients. Because the known SNP marker rs1143627 and the unannotated SNP rs549858786 have opposite effects (relative to each other) on IL1B expression, we performed an additional keyword search for $[54,63]$ "interleukin $1 \beta$ deficiency" as a biochemical marker relevant to medicine in the NCBI databases [4]. The result is shown in Table 1 and represents experimental findings [76] in a murine model of human rheumatoid arthritis, which showed an association of the interleukin $1 \beta$ deficiency with a high risk of this autoimmune disease. Within the framework of this animal model of the human disease [76], we propose rs549858786 as a candidate SNP marker of an increased risk of rheumatoid arthritis. This is the first novel finding in the present study.

Furthermore, the $I L 1 B$ promoter under study contains one more unannotated SNP $\operatorname{rs4986962}(-67 \mathrm{G} \rightarrow \mathrm{T})[3,4]$ that was predicted by our Web service [62] to insignificantly change TBP affinity for this promoter (data not shown). Notably, this prediction of (1)-(4) and Algorithm 1 does not rule out the possible usefulness of this SNP for clinical practice as a valid SNP marker of some human diseases. This is because our prediction does not take into account the influence of this SNP, for example, on the DNA sites binding to other transcription factors $[23,77]$, which can be studied in a different project, for example, using other Web services [25-27].

As one can see in Table 1, the next known SNP marker (of myocardial infarction and venous thromboembolism), rs563763767 $(-21 \mathrm{C} \rightarrow \mathrm{T})$ [78], is located within the corepromoter for transcript number 1 of the $F 3$ gene (coagulation factor F3; synonym: tissue factor) and has properties that are similar to those of the above-mentioned basic example. Using the Web service [62], we predicted the SNP-caused overexpression of this gene, in agreement with the known pathogenesis of these cardiovascular diseases [78]. In turn, the known SNP marker $-51 \mathrm{~T} \rightarrow \mathrm{C}$ within the core-promoter of the human NOS2 gene (inducible nitric oxide synthase 2) exemplifies the so-called balanced SNPs, which can have both beneficial (malaria resistance [79]) and adverse effects (epilepsy risk [80]) on human health. Another type of manifestations of SNPs is illustrated by the known SNP marker rs10168 $(-26 \mathrm{G} \rightarrow \mathrm{A})$ in the human DHFR gene (dihydrofolate reductase; the main target of methotrexate, which is the key drug for the treatment of children with acute lymphoblastic leukemia) [81]. This gene's overexpression as a result of $-26 \mathrm{~A}$ causes resistance to the above-mentioned antitumor drug. 
The known SNP marker rs10895068 of the human PGR gene exemplifies the SNP-caused de novo appearance of a spurious TBP-biding site along with the additional pathogenic TSS at position +270 from the normal TSS for transcript number 2 of the same gene [82]. This alternative TSS disrupts the balance between the $\alpha$ and $\beta$ isoforms of the progesterone receptor encoded by this gene; this aberration doubles the risk of endometrial cancer in overweight women [82].

Finally, the two bottom lines of Table 1 show two examples of the known SNP markers of so-called silent SNPs: $-20 \mathrm{~A} \rightarrow$ $\mathrm{T}$ within the promoter of the human CYP21A2 gene [83] and rs111426889, which precedes the alternative TSS located at position -120 upstream of the major TSS for transcript number 3 of the TNFRSF18 gene [84]. These silent SNPs are useful for monitoring of migration flows and ethnic composition of regional human subpopulations.

3.2. The Results on 22 Known Biomedical SNP Markers That Decrease TBP Affinity for Human Gene Promoters. The results on 22 known biomedical SNP markers that decrease TBP affinity for human gene promoters are presented in Table 2. Let us analyze them briefly referring to the above examples.

Some of these biomedical SNP markers (8 of 22; 36\%) were found within the promoters of two gene-paralogs: $H B B$ and $H B D$ of $\beta$ - and $\delta$-hemoglobins. As one can see in Table 2, all of them are "balanced SNPs" causing both resistance to malaria and thalassemia [85-96] with only one exception: substitution $-27 \mathrm{~A} \rightarrow \mathrm{T}$ is of the "silent SNP" type. In addition, the SNP marker rs 2814778 within the $D A R C$ gene is of the same "balanced SNP" type; namely, it is associated with malaria resistance and a low white-blood-cell count, as positive and negative effects on human health, respectively [97].

The known SNP marker rs28399433 (low risk of lung cancer among smokers) was found here within the human CYP2A6 gene (nicotine oxidase; synonyms: xenobiotic monooxygenase, polypeptide 6 of subfamily A of family 2 of cytochrome p450) [98, 99]. Our Web service [62] predicts (see (1)-(4) and Algorithm 1) reduced affinity of TBP for the minor allele of this gene promoter (Table 2). This result is consistent with empirical studies involving bioluminescence $[98,99]$. In addition, three known SNP markers, rs55999272 in the CRYGEP gene, rs2276109 in MMP12, and 18 bp deletion within the promoter of CETP, are associated with a reduced risk of Coppock-like cataract [100], asthma [101], systemic sclerosis [102], psoriasis [103], and atherosclerosis [104, 105] due to the SNP-caused damage to the TBP-binding sites of the promoters of these genes.

In addition, the known SNP marker rs34223104 within the core-promoter for the undocumented alternative TSS (located $48 \mathrm{bp}$ upstream of the major TSS of the CYP2B6 gene) transforms the canonical form (TATA-box) of the TBPbinding site, $5^{\prime}$-gatgaaatttTATAAcagggt- $3^{\prime}$, into the C\EBPbinding site ( $\backslash \mathrm{EBP}, \mathrm{CCAAT}-$ enhancer-binding protein), which causes increased bioactivation of the anticancer prodrug cyclophosphamide [106]. In this case, our Web service [62] predicts damage to this normal TBP-binding site that is in agreement within the experimentally observed transformation of this TBP-binding site into the SNP-caused $\mathrm{C} \backslash$ EBP-binding site [106].

Furthermore, the remaining six known SNP markers, rs7277748 (SOD1) [107], rs1800202 (TPI1) [108, 109], rs35036378 (ESR2) [110, 111], rs201739205 (HSD17B1) [112], rs72661131(MBL2) [113-115], and rs17537595 (ADH7) [116], including two substitutions, $-35 \mathrm{~A} \rightarrow \mathrm{C}(A P O A 1)$ [117] and $-33 \mathrm{~A} \rightarrow \mathrm{C}$ (F7) [118], are of the most frequent and best understood type of SNP: pathogenic damage to a normal TBP-binding site. This way, these SNPs can reduce expression of human genes.

Finally, near these 22 known biomedical SNP markers, we found and proposed 13 candidate SNP markers: rs63750953 $(H B B)$, rs281864525 (HBB), rs34166473 (HBD), rs55878706 (DARC), rs572527200 (MMP12), rs17231520 (CETP), rs569033466 (CETP), rs563558831 (CYP2B6), rs562962093 (MBL2), rs72661131 (MBL2), rs372329931 (ADH7), rs36773297 (F7), and rs549591993 (F7), as one can see in Table 2. About a half of them ( 8 of $13,62 \%$ ) have effects on gene expression that are codirectional with the effects of the nearby known SNP markers and thus can serve as markers of the same human diseases (e.g., rs562962093 and rs33931746). For the other half of the SNPs, we found associations with appropriate diseases [119, 120] using a keyword search $[54,63]$ in NCBI databases [4] (e.g., rs567653539).

3.3. The Results on 10 Known Biomedical SNP Markers That Insignificantly Change TBP Affinity for Human Gene Promoters. The results on 10 known biomedical SNP markers that insignificantly change TBP affinity for human gene promoters are presented in Table 3. Let us discuss them briefly.

First of all, the known SNP marker rs1394205 $(-29 \mathrm{G} \rightarrow \mathrm{A})$ within the FSHR gene belongs to one of the most important types of SNP: it causes a frequently occurring disease, for example, male infertility, and this connection has been proven clinically regardless of bioinformatic, biochemical, or any other nonclinical data. As shown in the first line of Table 3, in terms of this biomedical marker, there are no differences between fertile men (who are fathers) and infertile men in Italy [121] and in Turkey [122]. In agreement with these biomedical findings $[121,122]$, our Web service [62] (see (1)(4) and Algorithm 1) predicts no differences in TBP affinity for this gene's promoter between ancestral and minor alleles of this SNP.

The next four substitutions, $-48 \mathrm{G} \rightarrow \mathrm{C}(F 9),-42 \mathrm{~T} \rightarrow \mathrm{A}$ (F9), rs16887226 (StAR), and rs28399433 (GH1), are among the oldest known SNP markers that were discovered by means of the electrophoretic mobility shift assay (EMSA) before the advent of the reference human genome, gh19 [123, 124, 126]. According to these EMSA assays [123, 124, 126], each of these four SNPs pathologically reduces expression of the corresponding gene by disrupting the tissue-specific binding site for a transcription factor rather than by disrupting the ubiquitous TBP-binding site (they overlap). Additionally, the next five known SNP markers-rs1332018 (GSTM3), rs7586110 (UGT1A7), rs10465885 (GJA5), rs35594137 (GJA5), and rs13306848 (THBD)-have properties similar to those of the SNPs above, in terms of bioluminescence (LUC) assays [127-132] instead of EMSA. Here we found six nearby 
unannotated SNPs, rs371045754 (F9), rs544850971 (StAR), rs200209906 (GSTM3), rs574890114 (UGT1A7), rs542729995 (UGT1A7), and rs587745372 (GJA5), which can significantly disrupt the above-mentioned TBP-binding sites and thereby may cause the same diseases in humans as do the six candidate SNP markers (Table 3).

Finally, the last two biomedical SNP markersrs587745372 and rs398048306-taken together are the well-known unique genetic variation in the TBP-binding site length, $\mathrm{A}(\mathrm{TA})_{5-8} \mathrm{~A}$ in comparison with the norm: $\mathrm{A}(\mathrm{TA})_{7} \mathrm{~A}$. The longest of them, rs587745372, is an integral part of several haplotypes associated with a high risk of hyperbilirubinemia and jaundice [133], whereas two shortest ones, rs398048306 and rs200209906, are "silent SNPs" that are used to study ethnic differences of regional human subpopulations ([12] and Table 3).

Thus, in the vicinity of the 40 known biomedical SNP markers within the TBP-binding sites in humans, we first found 17 candidate SNP markers: rs55878706 (malaria resistance, low white-blood-cell count), rs562962093 (stroke, preeclampsia, and variable immunodeficiency), rs563558831 (cyclophosphamide bioactivation), rs549858786 (rheumatoid arthritis), rs372329931 (esophageal cancer), rs72661131 (cardiovascular events in rheumatoid arthritis), rs200209906 (brain, lung, testicular, and renal cell carcinomas), rs572527200 (low risk of asthma, systemic sclerosis, and psoriasis), rs371045754 (Leiden hemophilia B), rs587745372 (cardiovascular problems), rs367732974 and rs549591993 (both: progression of colorectal cancer from a primary tumor to metastasis), rs17231520 and rs569033466 (both: atherosclerosis), and rs63750953, rs281864525, and rs34166473 (all three: malaria resistance, thalassemia). This is the main result of our study.

\section{Discussion}

Because the mainstream method of searching for candidate SNP markers is now based on a statistical estimate of the similarity between the projections of unannotated SNPs and known SNP markers on various genome-wide maps, here we simplified the procedure by limiting it to unannotated SNPs only that are located near the known SNP markers in the TBPbinding sites of human genes. Within this framework, we found and analyzed 40 known SNP markers and 163 nearby unannotated SNPs shown within the first column of Tables 13 below the gene acronyms. The majority of the unannotated SNPs (153 of 203; 75\%) appear to be insignificantly altering TBP affinity for the core-promoter of the corresponding gene in humans (data not shown). This prediction of our Web service [62] seems to be consistent with the commonly accepted paradigm of genetic stability of the human genome and with data from EMSA and LUC assays of SNP-caused pathological disruption of binding sites for tissue-specific transcription factors rather than disruption of the TBPbinding site (overlaps them; they constitute the so-called composite unit [134]; Table 3).

The second most frequent group of SNP markers, 37 of 203 (18\%), disrupts TBP-binding sites within core-promoters of human genes and thereby reduces expression of these genes; this deficient gene expression is more often associated with adverse than beneficial effects on human health. This finding is in agreement with the commonly accepted bioinformatics notion that the SNP-caused damage to genetic information is more frequent than SNP-caused genetic benefits.

The third most frequent group of SNP markers, 13 of 203 (7\%), increases the TBP binding affinity for core-promoters of human genes and, hence, causes overexpression of these genes. This overexpression can be pathogenic, neutral, or beneficial for human health at approximately equal probabilities. This finding points to huge diversity of genetic effects of SNPs within the human genome. Indeed, the remaining manifestations of SNPs constitute only rare examples, such as "silent SNPs" (e.g., rs111426889), "balanced SNPs" (e.g., rs35518301), a de novo occurrence of a spurious TBP-biding site (e.g., rs10895068), transformation of a normal TBPbinding site into another regulatory genomic signal (e.g., rs34223104), a change of the composite unit containing the TBP-binding site (e.g., rs28399433), a deletion of the DNA fragment either around or inside the TBP-binding site (e.g., rs63750953), and a duplication of the DNA fragment inside the TBP-binding site (e.g., rs34983651).

As for the SNP-caused pathological changes, the majority (40 of 57; 70\%) of the SNP markers of diseases are either increasing or decreasing the risk of human diseases, whereas the rare types of SNPs are associated with drug resistance (e.g., rs10168), prodrug bioactivation (e.g., rs34223104), disease complications (e.g., rs72661131), and ethnic differences (e.g., rs398048306 and rs34223104). In addition, 10 of the 17 proposed candidate SNP markers are codirectionally changing TBP affinity for the core-promoters of human genes with respect to the nearby known SNP markers, whereas the remaining 7 candidate SNP markers do so in the opposite direction. Accordingly, we did additional keyword searches [54, 63] by hand in NCBI databases [4]. Both of these observations mean that our Web service [62], when combined with a manual comprehensive search for keywords $[54,63]$ by means of the Web-based information sources, is most suitable for precise analysis of specific SNPs, genes, and diseases rather than for a whole-genome search for a wide range of all possible manifestations of any unannotated SNPs.

In this regard, it should be noted that the statistical significance of the proposed 17 candidate SNP markers varies from high confidence $\left(\alpha<10^{-7}\right)$ to borderline significance $(\alpha<0.05)$. In contrast, $K_{D}$ values when expressed in moles $(M$; representing affinity of TBP binding to the corepromoter in vitro [50]) vary from $1 \mathrm{nM}$ to $62 \mathrm{nM}$, and their variation among alleles of a given SNP is less than $2 \%$ of this range and thus outside the limits of accuracy of empirical measurement of $K_{D}$ values, if we are not taking into account additional information on the expected range of the values being measured. Thus, the $K_{D}$ values shown in Tables 13 are necessary for prognostic affinity analysis of these 17 candidate SNP markers that we made using the Web service [62] for the purpose of their empirical verification by means of sophisticated equipment (e.g., [50-53]).

Finally, our estimates for the 17 candidate SNP markers (Tables $1-3)$ are only measures of bioinformatic $\left(K_{D}\right.$-values, 
$Z$-score, $\alpha$-value, $p$ value, etc.) and biomedical justification (last columns in Tables 1-3) for the highly expensive and laborious verification of SNPs during a search for an SNP marker that can be validated only by a higher incidence in patients than in healthy people. What is healthy or normal depends on ethnic, social, age, and gender composition of a human subpopulation, the settlement ratio and the associated migration flows, climate and environment, living conditions and lifestyle, the technological level of health care and diagnostic procedures, anamnesis, and treatment history [135].

\section{Conclusions}

The use of biomedical SNP markers can improve effectiveness of treatment and help to develop new medications. The majority of known SNP markers are located in proteincoding regions of human genes and have invariant manifestation of disruption in the protein structure and/or function (e.g., [29]). At the same time, only a minority of known SNP markers are located in regulatory regions of genes because their experimental detection is complicated by the tissueand developmental-stage-specific variation in binding of a regulatory protein to the these DNA regions $[23,25,27,30$, 77]. Nevertheless, the best-studied regulatory SNPs in TBPbinding sites of human promoters seem to have a lot in common with the SNPs in protein-coding regions rather than with the remaining regulatory SNPs. With this in mind, here we first predicted 17 candidate biomedical SNP markers in TBP-binding sites of human promoters and confirmed them using both clinical and basic research of other investigators (Tables 1-3). Verification of these predictions according to established biomedical standards and protocols can bridge the gap between the best-studied SNPs within protein-coding regions of human genes and the worst-studied regulatory SNPs and thus may advance postgenomic predictive preventive personalized medicine.

\section{Conflict of Interests}

The authors declare that the research was conducted in the absence of any commercial or financial relationships that could be construed as a potential conflict of interests.

\section{Acknowledgments}

The authors are grateful to Nikolai A. Shevchuk for English translation and editing and to Dr. Alena D. Zolotarenko for her fruitful ideas. Writing of the paper was supported by Project no. 14-04-00485 (for Ludmila Savinkova and Mikhail Ponomarenko) from the Russian Foundation for Basic Research. The software development was supported by Project no. 14-24-00123 (for Dmitry Rasskazov) from the Russian Scientific Foundation. The data compilation was supported by Project VI.58.1.2 (for Olga Arkova) and the data processing and analysis were supported by Project VI.61.1.2 (for Nikolay Kolchanov and Valentin Suslov, resp.), both from the Russian State Budget.

\section{References}

[1] S. Mallal, D. Nolan, C. Witt et al., "Association between presence of HLA-B ${ }^{*} 5701, H L A-D R 7$, and HLA-DQ3 and hypersensitivity to HIV-1 reverse-transcriptase inhibitor abacavir," The Lancet, vol. 359, no. 9308, pp. 727-732, 2002.

[2] G. M. Trovato, "Sustainable medical research by effective and comprehensive medical skills: overcoming the frontiers by predictive, preventive and personalized medicine," EPMA Journal, vol. 5, no. 1, article 14, 2014.

[3] V. Colonna, Q. Ayub, Y. Chen et al., "Human genomic regions with exceptionally high levels of population differentiation identified from 911 whole-genome sequences," Genome Biology, vol. 15, no. 6, article R88, 2014.

[4] NCBI Resource Coordinators, "Database resources of the National Center for Biotechnology Information," Nucleic Acids Research, vol. 43, pp. D6-D17, 2015.

[5] P. Flicek, M. R. Amode, D. Barrell et al., "Ensembl 2011," Nucleic Acids Research, vol. 39, pp. D800-D806, 2011.

[6] J. Harrow, A. Frankish, J. M. Gonzalez et al., "GENCODE: the reference human genome annotation for the ENCODE project," Genome Research, vol. 22, no. 9, pp. 1760-1774, 2012.

[7] T. R. Dreszer, D. Karolchik, A. S. Zweig et al., "The UCSC Genome Browser database: extensions and updates 2011," Nucleic Acids Research, vol. 40, no. 1, pp. D918-D923, 2012.

[8] D. Welter, J. MacArthur, J. Morales et al., "The NHGRI GWAS Catalog, a curated resource of SNP-trait associations," Nucleic Acids Research, vol. 42, no. 1, pp. D1001-D1006, 2014.

[9] J. S. Amberger, C. A. Bocchini, F. Schiettecatte, A. F. Scott, and A. Hamosh, "OMIM.org: Online Mendelian Inheritance in Man (OMIM), an online catalog of human genes and genetic disorders," Nucleic Acids Research, vol. 43, pp. D789-D798, 2015.

[10] M. J. Landrum, J. M. Lee, G. R. Riley et al., "ClinVar: public archive of relationships among sequence variation and human phenotype," Nucleic Acids Research, vol. 42, no. 1, pp. D980D985, 2014.

[11] D. M. Altshuler, R. A. Gibbs, L. Peltonen et al., "Integrating common and rare genetic variation in diverse human populations," Nature, vol. 467, no. 7311, pp. 52-58, 2010.

[12] N. Kaniwa, K. Kurose, H. Jinno et al., "Racial variability in haplotype frequencies of UGT1A1 and glucuronidation activity of a novel single nucleotide polymorphism 686C > T (P229L) found in an African-American," Drug Metabolism and Disposition, vol. 33, no. 3, pp. 458-465, 2005.

[13] Y. Ni, A. W. Hall, A. Battenhouse, and V. R. Iyer, "Simultaneous SNP identification and assessment of allele-specific bias from ChIP-seq data," BMC Genetics, vol. 13, article 46, 2012.

[14] J. Hu, J. W. Locasale, J. H. Bielas et al., "Heterogeneity of tumorinduced gene expression changes in the human metabolic network," Nature Biotechnology, vol. 31, no. 6, pp. 522-529, 2013.

[15] M. Hein and S. Graver, "Tumor cell response to bevacizumab single agent therapy in vitro," Cancer Cell International, vol. 13, no. 1, article 94, 2013.

[16] C.-Y. Chen, I.-S. Chang, C. A. Hsiung, and W. W. Wasserman, "On the identification of potential regulatory variants within genome wide association candidate SNP sets," BMC Medical Genomics, vol. 7, article 34, 2014.

[17] M. C. Andersen, P. G. Engström, S. Lithwick et al., "In silico detection of sequence variations modifying transcriptional regulation," PLoS Computational Biology, vol. 4, no. 1, article e5, 2008. 
[18] G. Macintyre, J. Bailey, I. Haviv, and A. Kowalczyk, "is-rSNP: a novel technique for in silico regulatory SNP detection," Bioinformatics, vol. 26, no. 18, pp. i524-i530, 2010.

[19] A. P. Boyle, E. L. Hong, M. Hariharan et al., "Annotation of functional variation in personal genomes using RegulomeDB," Genome Research, vol. 22, no. 9, pp. 1790-1797, 2012.

[20] A. Riva, "Large-scale computational identification of regulatory SNPs with rSNP-MAPPER," BMC Genomics, vol. 13, supplement 4, article S7, 2012.

[21] Y. Fu, Z. Liu, S. Lou et al., "FunSeq2: a framework for prioritizing noncoding regulatory variants in cancer," Genome Biology, vol. 15, no. 10, article 480, 2014.

[22] C.-C. Chen, S. Xiao, D. Xie et al., "Understanding variation in transcription factor binding by modeling transcription factor genome-epigenome interactions," PLoS Computational Biology, vol. 9, no. 12, Article ID e1003367, 2013.

[23] J. V. Ponomarenko, G. V. Orlova, T. I. Merkulova et al., "rSNP_Guide: an integrated database-tools system for studying SNPs and site-directed mutations in transcription factor binding sites," Human Mutation, vol. 20, no. 4, pp. 239-248, 2002.

[24] J. V. Ponomarenko, G. V. Orlova, A. S. Frolov, M. S. Gelfand, and M. P. Ponomarenko, "SELEX_DB: a database on in vitro selected oligomers adapted for recognizing natural sites and for analyzing both SNPs and site-directed mutagenesis data," Nucleic Acids Research, vol. 30, no. 1, pp. 195-199, 2002.

[25] D. A. Rasskazov, E. V. Antontseva, L. O. Bryzgalov et al., "rSNP_ guide-based evaluation of SNPs in promoters of the human APC and MLH1 genes associated with colon cancer," Russian Journal of Genetics: Applied Research, vol. 4, no. 4, pp. 245-253, 2014.

[26] N. L. Podkolodnyy, D. A. Afonnikov, Y. Y. Vaskin et al., "Program complex SNP-MED for analysis of single-nucleotide polymorphism (SNP) effects on the function of genes associated with socially significant diseases," Russian Journal of Genetics: Applied Research, vol. 4, no. 3, pp. 159-167, 2014.

[27] L. O. Bryzgalov, E. V. Antontseva, M. Y. Matveeva et al., "Detection of regulatory SNPs in human genome using ChIPseq ENCODE data," PloS ONE, vol. 8, no. 10, Article ID e78833, 2013.

[28] M. P. Ponomarenko, J. V. Ponomarenko, A. S. Frolov et al., "Oligonucleotide frequency matrices addressed to recognizing functional DNA sites," Bioinformatics, vol. 15, no. 7-8, pp. 631643, 1999.

[29] H. Mitsuyasu, K. Izuhara, X. Q. Mao et al., "Ile50Val variant of IL4R alpha upregulates IgE synthesis and associates with atopic asthma," Nature Genetics, vol. 19, no. 2, pp. 119-120, 1998.

[30] D. R. Zerbino, S. P. Wilder, N. Johnson, T. Juettemann, and P. R. Flicek, "The ensembl regulatory build," Genome Biology, vol. 16, article 56, 2015.

[31] M. M. Babu, N. M. Luscombe, L. Aravind, M. Gerstein, and S. A. Teichmann, "Structure and evolution of transcriptional regulatory networks," Current Opinion in Structural Biology, vol. 14, no. 3, pp. 283-291, 2004.

[32] M. Ponomarenko, V. Mironova, K. Gunbin, and L. Savinkova, "Hogness box," in Brenner's Encyclopedia of Genetics, S. Maloy and K. Hughes, Eds., vol. 3, pp. 491-494, Academic Press, Elsevier Inc, San Diego, Calif, USA, 2013.

[33] M. Ponomarenko, L. Savinkova, and N. Kolchanov, "Initiation Factors," in Brenner's Encyclopedia of Genetics, S. Maloy and K. Hughes, Eds., vol. 4, pp. 83-85, Academic Press, San Diego, Calif, USA, 2nd edition, 2013.
[34] I. Martianov, S. Viville, and I. Davidson, "RNA polymerase II transcription in murine cells lacking the TATA binding protein," Science, vol. 298, no. 5595, pp. 1036-1039, 2002.

[35] F. Müller, L. Lakatos, J.-C. Dantonel, U. Strähle, and L. Tora, "TBP is not universally required for zygotic RNA polymerase II transcription in zebrafish," Current Biology, vol. 11, no. 4, pp. 282-287, 2001.

[36] H. S. Rhee and B. F. Pugh, "Genome-wide structure and organization of eukaryotic pre-initiation complexes," Nature, vol. 483, no. 7389, pp. 295-301, 2012.

[37] M.-A. Choukrallah, D. Kobi, I. Martianov et al., "Interconversion between active and inactive TATA-binding protein transcription complexes in the mouse genome," Nucleic Acids Research, vol. 40, no. 4, pp. 1446-1459, 2012.

[38] M. Q. Yang, K. Laflamme, V. Gotea et al., "Genome-wide detection of a TFIID localization element from an initial human disease mutation," Nucleic Acids Research, vol. 39, no. 6, pp. 2175-2187, 2011.

[39] B. F. Pugh, "Control of gene expression through regulation of the TATA-binding protein," Gene, vol. 255, no. 1, pp. 1-14, 2000.

[40] J. J. Stewart and L. A. Stargell, "The stability of the TFIIA-TBPDNA complex is dependent on the sequence of the TATAAA element," The Journal of Biological Chemistry, vol. 276, no. 32, pp. 30078-30084, 2001.

[41] I. Mogno, F. Vallania, R. D. Mitra, and B. A. Cohen, "TATA is a modular component of synthetic promoters," Genome Research, vol. 20, no. 10, pp. 1391-1397, 2010.

[42] A. A. Sokolenko, I. I. Sandomirskii, and L. K. Savinkova, "Interaction of yeast TATA-binding protein with short promotor segments," Molekuliarnaia B iologiia, vol. 30, no. 2, pp. 279-285, 1996.

[43] M. P. Ponomarenko, J. V. Ponomarenko, A. S. Frolov et al., "Identification of sequence-dependent DNA features correlating to activity of DNA sites interacting with proteins," Bioinformatics, vol. 15, no. 7-8, pp. 687-703, 1999.

[44] L. K. Savinkova, I. A. Drachkova, M. P. Ponomarenko et al., "Interaction of recombinant TATA-binding protein with the TATA boxes of the of mammalian gene promoters," Ecological Genetics (St. Petersburg, Russia), vol. 4, pp. 44-49, 2007.

[45] J. V. Ponomarenko, D. P. Furman, A. S. Frolov et al., "ACTIVITY: a database on DNA/RNA sites activity adapted to apply sequence-activity relationships from one system to another," Nucleic Acids Research, vol. 29, no. 1, pp. 284-287, 2001.

[46] M. P. Ponomarenko, L. K. Savinkova, Y. V. Ponomarenko, A. E. Kel', I. I. Titov, and N. A. Kolchanov, "Simulation of TATA box sequences in eukaryotes," Molecular Biology, vol. 31, no. 4, pp. 616-622, 1997.

[47] P. M. Ponomarenko, L. K. Savinkova, I. A. Drachkova et al., "A step-by-step model of TBP/TATA box binding allows predicting human hereditary diseases by single nucleotide polymorphism," Doklady Biochemistry and Biophysics, vol. 419, no. 1, pp. 88-92, 2008.

[48] P. Bucher, "Weight matrix descriptions of four eukaryotic RNA polymerase II promoter elements derived from 502 unrelated promoter sequences," Journal of Molecular Biology, vol. 212, no. 4, pp. 563-578, 1990.

[49] R. F. Delgadillo, J. E. Whittington, L. K. Parkhurst, and L. J. Parkhurst, "The TATA-binding protein core domain in solution variably bends TATA sequences via a three-step binding mechanism," Biochemistry, vol. 48, no. 8, pp. 1801-1809, 2009. 
[50] L. K. Savinkova, I. A. Drachkova, T. V. Arshinova, P. Ponomarenko, M. Ponomarenko, and N. Kolchanov, "An experimental verification of the predicted effects of promoter TATA-box polymorphisms associated with human diseases on interactions between the TATA boxes and TATA-binding protein," PLoS ONE, vol. 8, no. 2, Article ID e54626, 2013.

[51] I. Drachkova, L. Savinkova, T. Arshinova, M. Ponomarenko, S. Peltek, and N. Kolchanov, "The mechanism by which TATAbox polymorphisms associated with human hereditary diseases influence interactions with the TATA-binding protein," Human Mutation, vol. 35, no. 5, pp. 601-608, 2014.

[52] I. A. Drachkova, S. V. Shekhovtsov, S. E. Peltek et al., "Surface plasmon resonance study of the interaction between the human TATA-box binding protein and the TATA element of the NOS2A gene promoter," Vavilov Journal of Genetics and Breeding, vol. 16, no. 2, pp. 391-396, 2012.

[53] O. V. Arkova, N. A. Kuznetsov, O. S. Fedorova, N. A. Kolchanov, and L. K. Savinkova, "Real-time interaction between TBP and the TATA box of the human triosephosphate isomerase gene promoter in the norm and pathology," Acta Naturae, vol. 6, no. 2, pp. 36-40, 2014.

[54] L. K. Savinkova, M. P. Ponomarenko, P. M. Ponomarenko et al., "TATA box polymorphisms in human gene promoters and associated hereditary pathologies," Biochemistry, vol. 74, no. 2, pp. 117-129, 2009.

[55] V. V. Suslov, P. M. Ponomarenko, V. M. Efimov, L. K. Savinkova, M. P. Ponomarenko, and N. A. Kolchanov, "SNPS in the HIV-1 tata box and the aids pandemic," Journal of Bioinformatics and Computational Biology, vol. 8, no. 3, pp. 607-625, 2010.

[56] V. V. Suslov, P. M. Ponomarenko, M. P. Ponomarenko et al., "TATA box polymorphisms in genes of commercial and laboratory animals and plants associated with selectively valuable traits," Russian Journal of Genetics, vol. 46, no. 4, pp. 394-403, 2010.

[57] P. M. Ponomarenko, M. P. Ponomarenko, I. A. Drachkova et al., "Prediction of the affinity of the TATA-binding protein to TATA boxes with single nucleotide polymorphisms," Molecular Biology, vol. 43, no. 3, pp. 472-479, 2009.

[58] M. P. Ponomarenko, V. V. Suslov, K. V. Gunbin et al., "Identification of the relationship between variability of expression of signaling pathway genes in the human brain and affinity of TATA-binding protein to their promoters," Vavilov Journal of Genetics and Breeding, vol. 18, no. 3-4, pp. 1219-1230, 2014.

[59] V. V. Mironova, N. A. Omelyanchuk, P. M. Ponomarenko, M. P. Ponomarenko, and N. A. Kolchanov, "Specific/nonspecific binding of TBP to promoter DNA of the auxin response factor genes in plants correlated with ARFs function on gene transcription (activator/repressor)," Doklady Biochemistry and Biophysics, vol. 433, no. 1, pp. 191-196, 2010.

[60] P. M. Ponomarenko and M. P. Ponomarenko, "Sequence-based prediction of transcription upregulation by auxin in plants," Journal of Bioinformatics and Computational Biology, vol. 13, no. 1, Article ID 1540009, 2015.

[61] P. M. Ponomarenko, V. V. Suslov, L. K. Savinkova, M. P. Ponomarenko, and N. A. Kolchanov, "A precise equation of equilibrium of four steps of TBP binding with the TATA box for prognosis of phenotypic manifestation of mutations," Biophysics, vol. 55, no. 3, pp. 358-369, 2010.

[62] D. A. Rasskazov, K. V. Gunbin, P. M. Ponomarenko et al., "SNP_TATA_COMPARATOR: web-service for comparison of SNPs within gene promoters associated with human diseases using the equilibrium equation of the TBP/TATA complex,"
Vavilov Journal of Genetics and Breeding, vol. 17, no. 4/1, pp. 599606, 2013.

[63] I. Missala, U. Kassner, and E. Steinhagen-Thiessen, "A systematic literature review of the association of lipoprotein(a) and autoimmune diseases and atherosclerosis," International Journal of Rheumatology, vol. 2012, Article ID 480784, 10 pages, 2012.

[64] J. E. Stajich, D. Block, K. Boulez et al., “The Bioperl toolkit: perl modules for the life sciences," Genome Research, vol. 12, no. 10, pp. 1611-1618, 2002.

[65] D. Flatters and R. Lavery, "Identification of sequence-dependent features correlating to activity of DNA sites interacting with proteins," Biophysical Journal, vol. 75, no. 1, pp. 372-381, 1998.

[66] S. Hahn, S. Buratowski, P. A. Sharp, and L. Guarente, "Yeast TATA-binding protein TFIID binds to TATA elements with both consensus and nonconsensus DNA sequences," Proceedings of the National Academy of Sciences of the United States of America, vol. 86, no. 15, pp. 5718-5722, 1989.

[67] R. A. Coleman and B. F. Pugh, "Evidence for functional binding and stable sliding of the TATA binding protein on nonspecific DNA," The Journal of Biological Chemistry, vol. 270, no. 23, pp. 13850-13859, 1995.

[68] H. Karas, R. Knüppel, W. Schulz, H. Sklenar, and E. Wingender, "Combining structural analysis of DNA with search routines for the detection of transcription regulatory elements," Computer Applications in the Biosciences, vol. 12, no. 5, pp. 441-446, 1996.

[69] IUPAC-IUB Commission on Biochemical Nomenclature (CBN), "Abbreviations and Symbols for nucleic acids, polynucleotides and their constituents," Journal of Molecular Biology, vol. 55, no. 3, pp. 299-310, 1971.

[70] E. M. El-Omar, M. Carrington, W.-H. Chow et al., "Interleukin1 polymorphisms associated with increased risk of gastric cancer," Nature, vol. 404, no. 6776, pp. 398-402, 2000.

[71] Y. Wang, N. Kato, Y. Hoshida et al., "Interleukin-1 $\beta$ gene polymorphisms associated with hepatocellular carcinoma in hepatitis C virus infection," Hepatology, vol. 37, no. 1, pp. 65-71, 2003.

[72] K.-S. Wu, X. Zhou, F. Zheng, X.-Q. Xu, Y.-H. Lin, and J. Yang, "Influence of interleukin-1 beta genetic polymorphism, smoking and alcohol drinking on the risk of non-small cell lung cancer," Clinica Chimica Acta, vol. 411, no. 19-20, pp. 1441-1446, 2010.

[73] D. N. Martínez-Carrillo, E. Garza-González, R. BetancourtLinares et al., "Association of IL1B -511C/-31T haplotype and Helicobacter pylori vacA genotypes with gastric ulcer and chronic gastritis," BMC Gastroenterology, vol. 10, article 126, 2010.

[74] F. Hayashi, M. Watanabe, T. Nanba, N. Inoue, T. Akamizu, and Y. Iwatani, "Association of the $-31 \mathrm{C} / \mathrm{T}$ functional polymorphism in the interleukin-1beta gene with the intractability of Graves' disease and the proportion of T helper type 17 cells," Clinical and Experimental Immunology, vol. 158, no. 3, pp. 281-286, 2009.

[75] P. Borkowska, K. Kucia, S. Rzezniczek et al., "Interleukinlbeta promoter (-31T/C and $-511 \mathrm{C} / \mathrm{T})$ polymorphisms in major recurrent depression," Journal of Molecular Neuroscience, vol. 44, no. 1, pp. 12-16, 2011.

[76] H. Yamazaki, M. Takeoka, M. Kitazawa et al., "ASC plays a role in the priming phase of the immune response to type II collagen in collagen-induced arthritis," Rheumatology International, vol. 32, no. 6, pp. 1625-1632, 2012.

[77] G. V. Vasiliev, V. M. Merkulov, V. F. Kobzev, T. I. Merkulova, M. P. Ponomarenko, and N. A. Kolchanov, "Point mutations 
within 663-666 bp of intron 6 of the human TDO2 gene, associated with a number of psychiatric disorders, damage the YY-1 transcription factor binding site," FEBS Letters, vol. 462, no. 1-2, pp. 85-88, 1999.

[78] E. Arnaud, V. Barbalat, V. Nicaud et al., "Polymorphisms in the $5^{\prime}$ regulatory region of the tissue factor gene and the risk of myocardial infarction and venous thromboembolism: the ECTIM and PATHROS studies," Arteriosclerosis, Thrombosis, and Vascular Biology, vol. 20, no. 3, pp. 892-898, 2000.

[79] I. A. Clark, K. A. Rockett, and D. Burgner, "Genes, nitric oxide and malaria in African children," Trends in Parasitology, vol. 19, no. 8, pp. 335-337, 2003.

[80] J. A. González-Martínez, G. Möddel, Z. Ying, R. A. Prayson, W. E. Bingaman, and I. M. Najm, "Neuronal nitric oxide synthase expression in resected epileptic dysplastic neocortex: laboratory investigation," Journal of Neurosurgery, vol. 110, no. 2, pp. 343349, 2009.

[81] F. Al-Shakfa, S. Dulucq, I. Brukner et al., "DNA variants in region for noncoding interfering transcript of Dihydrofolate reductase gene and outcome in childhood acute lymphoblastic leukemia," Clinical Cancer Research, vol. 15, no. 22, pp. 69316938, 2009.

[82] I. De Vivo, G. S. Huggins, S. E. Hankinson et al., "A functional polymorphism in the promoter of the progesterone receptor gene associated with endometrial cancer risk," Proceedings of the National Academy of Sciences of the United States of America, vol. 99, no. 19, pp. 12263-12268, 2002.

[83] B. Blaskó, Z. Bánlaki, G. Gyapay et al., "Linkage analysis of the $C 4 A / C 4 B$ copy number variation and polymorphisms of the adjacent steroid 21-hydroxylase gene in a healthy population," Molecular Immunology, vol. 46, no. 13, pp. 2623-2629, 2009.

[84] T. P. Velavan, S. Bechlars, X. Huang, P. G. Kremsner, and J. F. J. Kun, "Novel regulatory SNPs in the promoter region of the TNFRSF18 gene in a gabonese population," Brazilian Journal of Medical and Biological Research, vol. 44, no. 5, pp. 418-420, 2011.

[85] Y. Yamashiro, Y. Hattori, Y. Matsuno et al., "Another example of Japanese beta-thalassemia [-31 Cap (A--G)]," Hemoglobin, vol. 13, no. 7-8, pp. 761-767, 1989.

[86] Y. Takihara, T. Nakamura, H. Yamada et al., "A novel mutation in the TATA box in a Japanese patient with beta +-thalassemia," Blood, vol. 67, no. 2, pp. 547-550, 1986.

[87] Y. J. Fei, T. A. Stoming, G. D. Efremov et al., " $\beta$-thalassemia due to a $\mathrm{T} \rightarrow$ A mutation within the ATA box," Biochemical and Biophysical Research Communications, vol. 153, no. 2, pp. 741747, 1988.

[88] S.-P. Cai, J.-Z. Zhang, M. Doherty, and Y. W. Kan, "A new TATA box mutation detected at prenatal diagnosis for $\beta$-thalassemia," The American Journal of Human Genetics, vol. 45, no. 1, pp. 112114, 1989.

[89] S. E. Antonarakis, S. H. Irkin, T. C. Cheng et al., "Betathalassemia in American blacks: novel mutations in the 'TATA' box and an acceptor splice site," Proceedings of the National Academy of Sciences of the United States of America, vol. 81, no. 4, pp. 1154-1158, 1984.

[90] S. Huang, C. Wong, S. E. Antonarakis, T. Ro-lien, W. H. Y. Lo, and H. H. Kazazian Jr., "The same "TATA” box $\alpha$-thalassemia mutation in Chinese and US blacks: another example of independent origins of mutation," Human Genetics, vol. 74, no. 2, pp. 162-164, 1986.

[91] S. H. Orkin, J. P. Sexton, T.-C. Cheng et al., "ATA box transcription mutation in $\beta$-thalassemia," Nucleic Acids Research, vol. 11, no. 14 , pp. 4727-4734, 1983.
[92] M. Poncz, M. Ballantine, D. Solowiejczyk, I. Barak, E. Schwartz, and S. Surrey, " $\beta$-Thalassemia in a Kurdish Jew. Single base changes in the T-A-T-A box," The Journal of Biological Chemistry, vol. 257, no. 11, pp. 5994-5996, 1982.

[93] F. S. Collins and S. M. Weissman, "The molecular genetics of human hemoglobin," Progress in Nucleic Acid Research and Molecular Biology, vol. 31, pp. 315-462, 1984.

[94] C. Badens, N. Jassim, N. Martini, J. F. Mattei, J. Elion, and D. Lena-Russo, "Characterization of a new polymorphism, IVS-I$108(\mathrm{~T} \rightarrow \mathrm{C})$, and a new $\beta$ - thalassemia mutation,-27 $(\mathrm{A} \rightarrow \mathrm{T})$, discovered in the course of a prenatal diagnosis," Hemoglobin, vol. 23, no. 4, pp. 339-344, 1999.

[95] R. M. Bannerman, L. M. Garrick, P. Rusnak-Smalley, J. E. Hoke, and J. A. Edwards, "Hemoglobin deficit: An inherited hypochromic anemia in the mouse," Proceedings of the Society for Experimental Biology and Medicine, vol. 182, no. 1, pp. 52-57, 1986.

[96] H. Frischknecht and F. Dutly, "Two new delta-globin mutations: Hb A2-Ninive [!delta133(H11)Val-Ala] and a delta(+)thalassemia mutation $[-31(A \rightarrow G)]$ in the TATA box of the delta-globin gene," Hemoglobin, vol. 29, no. 2, pp. 151-154, 2005.

[97] M. A. Nalls, J. G. Wilson, N. J. Patterson et al., "Admixture mapping of white cell count: genetic locus responsible for lower white blood cell count in the Health ABC and Jackson Heart studies," American Journal of Human Genetics, vol. 82, no. 1, pp. 81-87, 2008.

[98] M. Pitarque, O. von Richter, B. Oke, H. Berkkan, M. Oscarson, and M. Ingelman-Sundberg, "Identification of a single nucleotide polymorphism in the TATA box of the CYP2A6 gene: impairment of its promoter activity," Biochemical and Biophysical Research Communications, vol. 284, no. 2, pp. 455460, 2001.

[99] M. L. Pianezza, E. M. Sellers, and R. F. Tyndale, "Nicotine metabolism defect reduces smoking," Nature, vol. 393, no. 6687, p. $750,1998$.

[100] R. H. Brakenhoff, H. A. M. Henskens, M. W. P. C. Van Rossum, N. H. Lubsen, and J. G. G. Schoenmakers, "Activation of the gammaE-crystallin pseudogene in the human hereditary Coppock-like cataract," Human Molecular Genetics, vol. 3, no. 2, pp. 279-283, 1994.

[101] G. M. Hunninghake, M. H. Cho, Y. Tesfaigzi et al., "MMP12, lung function, and COPD in high-risk populations," The New England Journal of Medicine, vol. 361, no. 27, pp. 2599-2608, 2009.

[102] M. Manetti, L. Ibba-Manneschi, C. Fatini et al., "Association of a functional polymorphism in the matrix metalloproteinase-12 promoter region with systemic sclerosis in an Italian population," Journal of Rheumatology, vol. 37, no. 9, pp. 1852-1857, 2010.

[103] N. L. Starodubtseva, V. V. Sobolev, A. G. Soboleva, A. A. Nikolaev, and S. A. Bruskin, "Genes expression of metalloproteinases (MMP-1, MMP-2, MMP-9, and $M M P-12)$ associated with psoriasis," Russian Journal of Genetics, vol. 47, no. 9, pp. 1117-1123, 2011.

[104] W. Plengpanich, W. Le Goff, S. Poolsuk, Z. Julia, M. Guerin, and W. Khovidhunkit, "CETP deficiency due to a novel mutation in the CETP gene promoter and its effect on cholesterol efflux and selective uptake into hepatocytes," Atherosclerosis, vol. 216, no. 2, pp. 370-373, 2011.

[105] K. Oka, L. M. Belalcazar, C. Dieker et al., "Sustained phenotypic correction in a mouse model of hypoalphalipoproteinemia with a helper-dependent adenovirus vector," Gene Therapy, vol. 14, no. 3, pp. 191-202, 2007. 
[106] J. Zukunft, T. Lang, T. Richter et al., "A natural CYP2B6 TATA box polymorphism $(-82 \mathrm{~T} \rightarrow \mathrm{C})$ leading to enhanced transcription and relocation of the transcriptional start site," Molecular Pharmacology, vol. 67, no. 5, pp. 1772-1782, 2005.

[107] S. Niemann, W. J. Broom, and R. H. Brown Jr., "Analysis of a genetic defect in the TATA box of the SOD1 gene in a patient with familial amyotrophic lateral sclerosis," Muscle and Nerve, vol. 36, no. 5, pp. 704-707, 2007.

[108] M. Watanabe, B. C. Zingg, and H. W. Mohrenweiser, "Molecular analysis of a series of alleles in humans with reduced activity at the triosephosphate isomerase locus," The American Journal of Human Genetics, vol. 58, no. 2, pp. 308-316, 1996.

[109] J.-L. Vives-Corrons, H. Rubinson-Skala, M. Mateo, J. Estella, E. Feliu, and J.-C. Dreyfus, "Triosephosphate isomerase deficiency with hemolytic anemia and severe neuromuscular disease: familial and biochemical studies of a case found in Spain," Human Genetics, vol. 42, no. 2, pp. 171-180, 1978.

[110] S. Philips, A. Richter, S. Oesterreich et al., "Functional characterization of a genetic polymorphism in the promoter of the ESR2 gene," Hormones and Cancer, vol. 3, no. 1-2, pp. 37-43, 2012.

[111] A. M. Sieuwerts, M. Ansems, M. P. Look et al., "Clinical significance of the nuclear receptor co-regulator DC-SCRIPT in breast cancer: an independent retrospective validation study," Breast Cancer Research, vol. 12, no. 6, article R103, 2010.

[112] H. Peltoketo, Y. Piao, A. Mannermaa et al., "A point mutation in the putative TATA box, detected in nondiseased individuals and patients with hereditary breast cancer, decreases promoter activity of the $17 \beta$-hydroxysteroid dehydrogenase type 1 gene 2 (EDH17B2) in vitro," Genomics, vol. 23, no. 1, pp. 250-252, 1994.

[113] A. B. W. Boldt, L. Culpi, L. T. Tsuneto, I. R. de Souza, J. F. J. Kun, and M. L. Petzl-Erler, "Diversity of the MBL2 gene in various Brazilian populations and the case of selection at the mannosebinding lectin locus," Human Immunology, vol. 67, no. 9, pp. 722-734, 2006.

[114] A. Cervera, A. M. Planas, C. Justicia et al., "Geneticallydefined deficiency of mannose-binding lectin is associated with protection after experimental stroke in mice and outcome in human stroke," PLoS ONE, vol. 5, no. 2, Article ID e8433, 2010.

[115] I. Sziller, O. Babula, P. Hupuczi et al., "Mannose-binding lectin (MBL) codon 54 gene polymorphism protects against development of pre-eclampsia, HELLP syndrome and pre-eclampsiaassociated intrauterine growth restriction," Molecular Human Reproduction, vol. 13, no. 4, pp. 281-285, 2007.

[116] A. Abbas, M. Lechevrel, and F. Sichel, "Identification of new single nucleotid polymorphisms (SNP) in alcohol dehydrogenase class IV ADH7 gene within a French population," Archives of Toxicology, vol. 80, no. 4, pp. 201-205, 2006.

[117] A. Matsunaga, J. Sasaki, H. Han et al., "Compound heterozygosity for an apolipoprotein A1 gene promoter mutation and a structural nonsense mutation with apolipoprotein A1 deficiency," Arteriosclerosis, Thrombosis, and Vascular Biology, vol. 19, no. 2, pp. 348-355, 1999.

[118] A. Kavlie, L. Hiltunen, V. Rasi, and H. P. B. Prydz, "Two novel mutations in the human coagulation factor VII promoter," Thrombosis and Haemostasis, vol. 90, no. 2, pp. 194-205, 2003.

[119] L. N. Troelsen, P. Garred, B. Christiansen et al., "Double role of mannose-binding lectin in relation to carotid intima-media thickness in patients with rheumatoid arthritis," Molecular Immunology, vol. 47, no. 4, pp. 713-718, 2010.

[120] J. Q. Tang, Q. Fan, Y. L. Wan et al., "Ectopic expression and clinical significance of tissue factor/coagulation factor VII complex in colorectal cancer," Journal of Peking University: Health sciences, vol. 41, no. 5, pp. 531-536, 2009.

[121] M. Pengo, A. Ferlin, B. Arredi et al., "FSH receptor gene polymorphisms in fertile and infertile Italian men," Reproductive BioMedicine Online, vol. 13, no. 6, article 2494, pp. 795-800, 2006.

[122] M. Balkan, A. Gedik, H. Akkoc et al., "FSHR single nucleotide polymorphism frequencies in proven fathers and infertile men in southeast turkey," Journal of Biomedicine and Biotechnology, vol. 2010, Article ID 640318, 5 pages, 2010.

[123] M. J. Reijnen, F. M. Sladek, R. M. Bertina, and P. H. Reitsma, "Disruption of a binding site for hepatocyte nuclear factor 4 results in hemophilia B Leyden," Proceedings of the National Academy of Sciences of the United States of America, vol. 89, no. 14, pp. 6300-6303, 1992.

[124] A. J. Casal, V. J. P. Sinclair, A. M. Capponi, J. Nicod, U. HuynhDo, and P. Ferrari, "A novel mutation in the steroidogenic acute regulatory protein gene promoter leading to reduced promoter activity," Journal of Molecular Endocrinology, vol. 37, no. 1, pp. 71-80, 2006.

[125] K. M. Caron, S.-C. Soo, W. C. Wetsel, D. M. Stocco, B. J. Clark, and K. L. Parker, "Targeted disruption of the mouse gene encoding steroidogenic acute regulatory protein provides insights into congenital lipoid adrenal hyperplasia," Proceedings of the National Academy of Sciences of the United States of America, vol. 94, no. 21, pp. 11540-11545, 1997.

[126] M. Horan, D. S. Millar, J. Hedderich et al., "Human growth hormone 1 (GH1) gene expression: complex haplotype-dependent influence of polymorphic variation in the proximal promoter and locus control region," Human Mutation, vol. 21, no. 4, pp. 408-423, 2003.

[127] X. Liu, M. R. Campbell, G. S. Pittman, E. C. Faulkner, M. A. Watson, and D. A. Bell, "Expression-based discovery of variation in the human glutathione S-transferase M3 promoter and functional analysis in a glioma cell line using allele-specific chromatin immunoprecipitation," Cancer Research, vol. 65, no. 1, pp. 99-104, 2005.

[128] X. Tan, Y. Wang, Y. Han et al., "Genetic variation in the GSTM3 promoter confer risk and prognosis of renal cell carcinoma by reducing gene expression," British Journal of Cancer, vol. 109, no. 12, pp. 3105-3115, 2013.

[129] T. O. Lankisch, A. Vogel, S. Eilermann et al., "Identification and characterization of a functional TATA box polymorphism of the UDP glucuronosyltransferase 1A7 gene," Molecular Pharmacology, vol. 67, no. 5, pp. 1732-1739, 2005.

[130] R. C. Wirka, S. Gore, D. R. Van Wagoner et al., "A common connexin- 40 gene promoter variant affects connexin-40 expression in human atria and is associated with atrial fibrillation," Circulation: Arrhythmia and Electrophysiology, vol. 4, no. 1, pp. 87-93, 2011.

[131] M. Firouzi, H. Ramanna, B. Kok et al., "Association of human connexin 40 gene polymorphisms with atrial vulnerability as a risk factor for idiopathic atrial fibrillation," Circulation Research, vol. 95, no. 4, pp. e29-e33, 2004.

[132] L. Le Flem, V. Picard, J. Emmerich et al., "Mutations in promoter region of thrombomodulin and venous thromboembolic disease," Arteriosclerosis, Thrombosis, and Vascular Biology, vol. 19, no. 4, pp. 1098-1104, 1999.

[133] P. J. Bosma, J. R. Chowdhury, C. Barker et al., "The genetic basis of the reduced expression of bilirubin UDPglucuronosyltransferase 1 in Gilbert's syndrome," The New England Journal of Medicine, vol. 333, no. 18, pp. 1171-1175, 1995. 
[134] V. Matys, O. V. Kel-Margoulis, E. Fricke et al., "TRANSFAC and its module TRANSCompel: transcriptional gene regulation in eukaryotes," Nucleic Acids Research, vol. 34, pp. D108-D110, 2006.

[135] S. S. Yoo, C. Jin, D. K. Jung et al., "Putative functional variants of XRCC1 identified by RegulomeDB were not associated with lung cancer risk in a Korean population," Cancer Genetics, vol. 208, no. 1-2, pp. 19-24, 2015. 

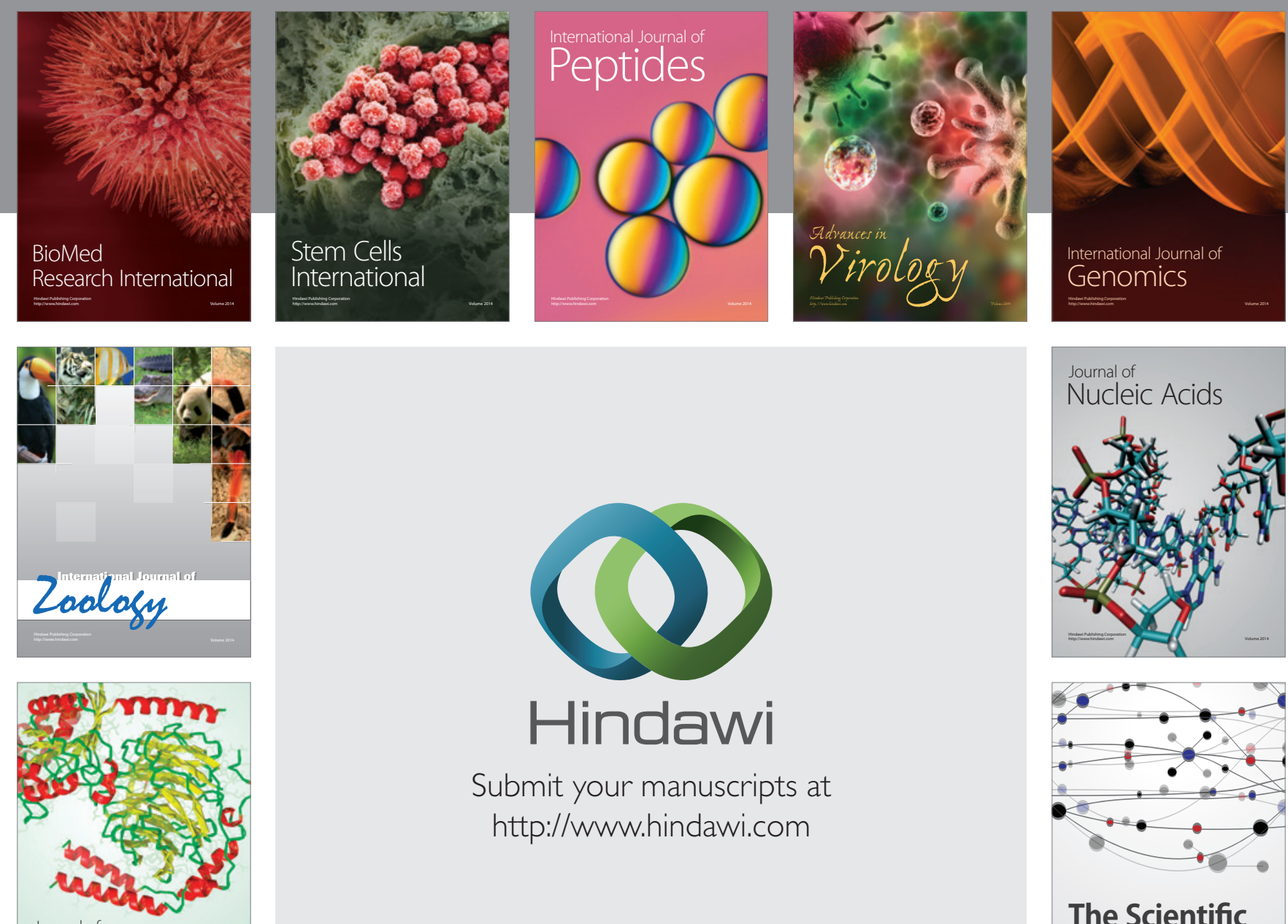

Submit your manuscripts at

http://www.hindawi.com

Journal of
Signal Transduction
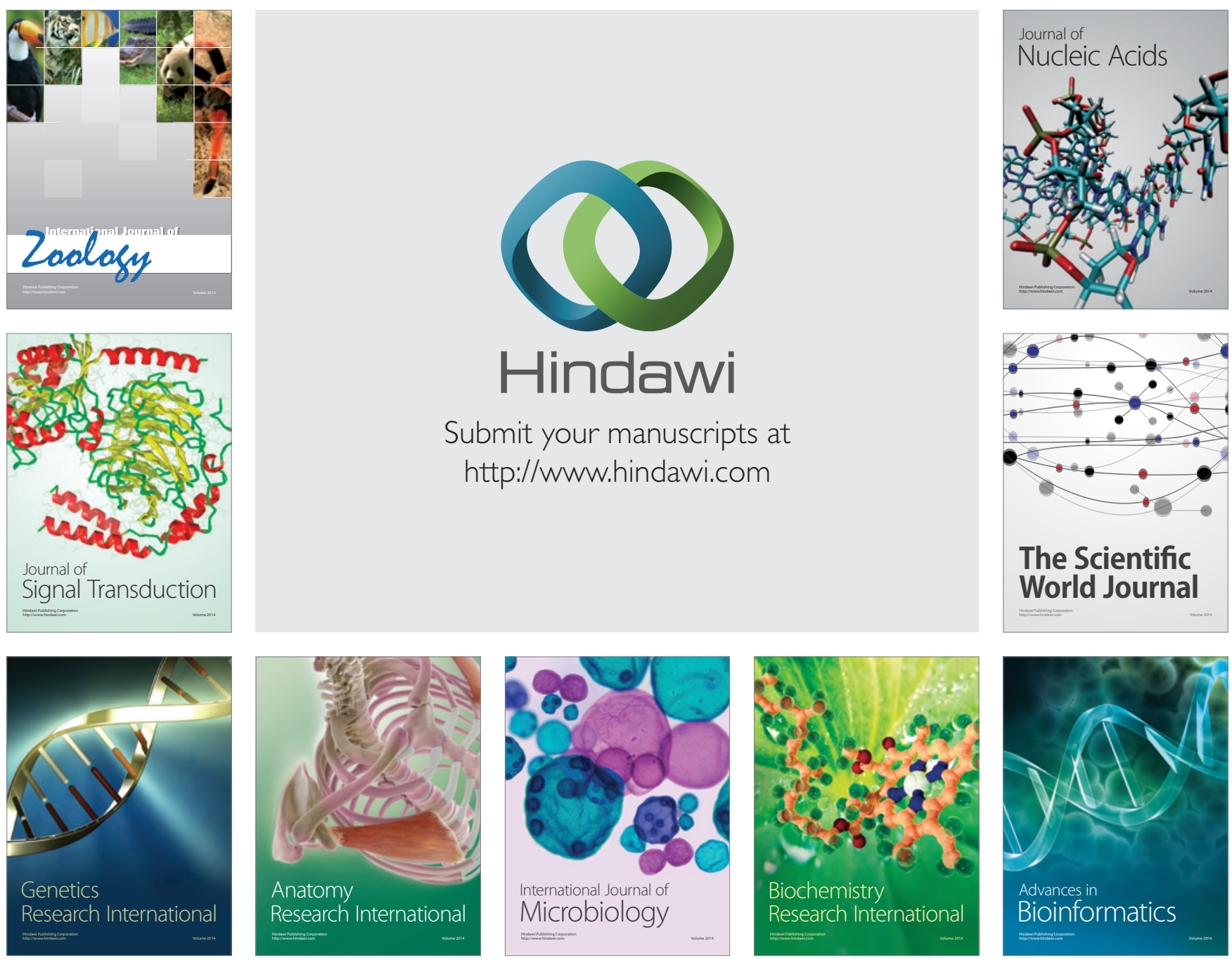

The Scientific World Journal
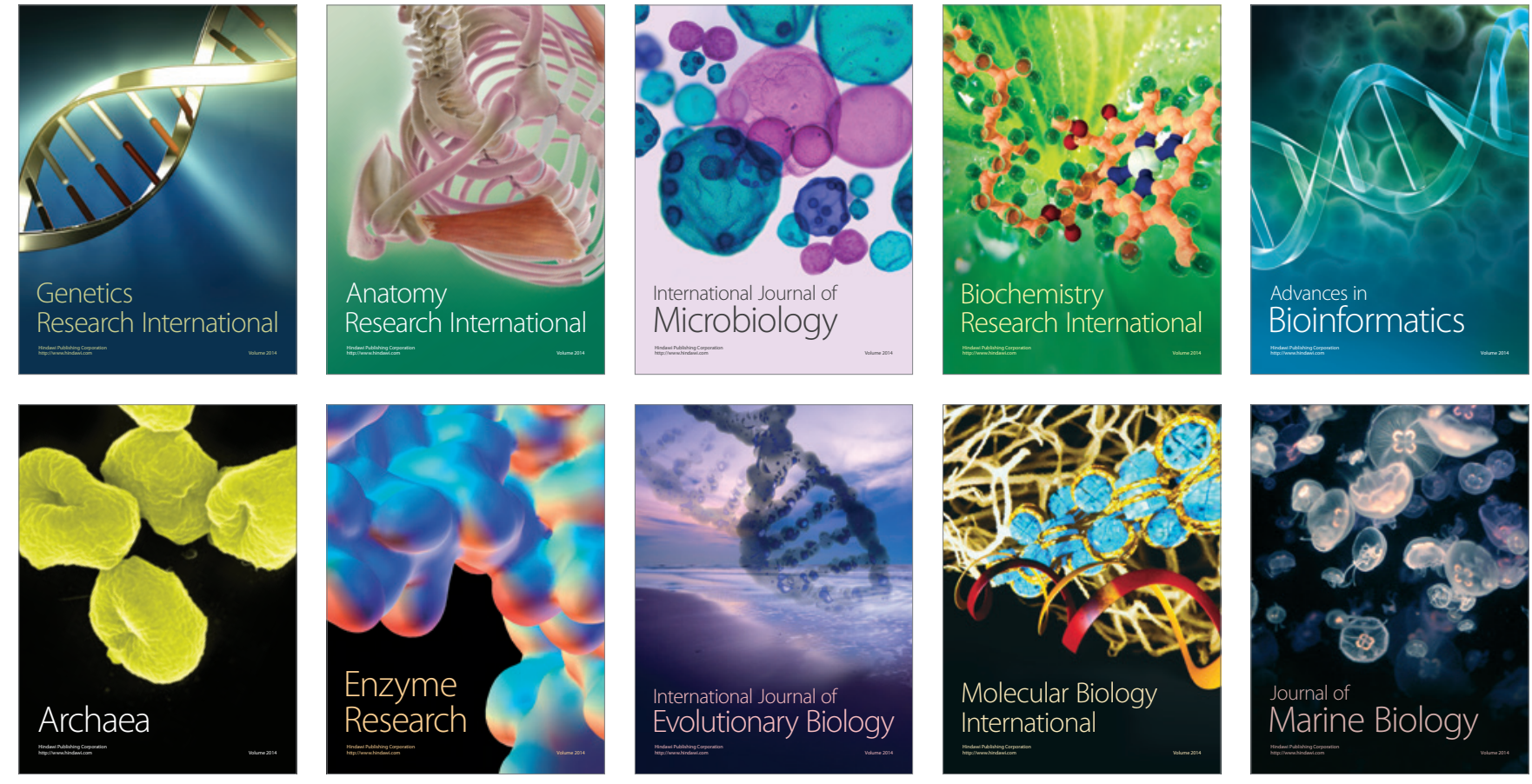